\title{
Effects of neonicotinoids and fipronil on non-target invertebrates
}

\author{
L. W. Pisa • V. Amaral-Rogers • L. P. Belzunces • J. M. Bonmatin • C. A. Downs • \\ D. Goulson • D. P. Kreutzweiser • C. Krupke • M. Liess • M. McField • C. A. Morrissey • \\ D. A. Noome • J. Settele • N. Simon-Delso • J. D. Stark • J. P. Van der Sluijs • H. Van Dyck • \\ M. Wiemers
}

Received: 8 May 2014 / Accepted: 15 August 2014 / Published online: 17 September 2014

(C) Springer-Verlag Berlin Heidelberg 2014

\begin{abstract}
We assessed the state of knowledge regarding the effects of large-scale pollution with neonicotinoid insecticides and fipronil on non-target invertebrate species of terrestrial, freshwater and marine environments. A large section of the assessment is dedicated to the state of knowledge on sublethal effects on honeybees (Apis mellifera) because this important pollinator is the most studied non-target invertebrate species.
\end{abstract}

Responsible editor: Philippe Garrigues

L. W. Pisa $(\bowtie) \cdot$ N. Simon-Delso $\cdot$ J. P. Van der Sluijs

Environmental Sciences, Copernicus Institute, Utrecht University,

Heidelberglaan 2, 3584 CS Utrecht, The Netherlands

e-mail: 1.w.pisa@uu.nl

\section{Amaral-Rogers}

Buglife, Bug House, Ham Lane, Orton Waterville, Peterborough PE2

$5 \mathrm{UU}, \mathrm{UK}$

\section{P. Belzunces}

Laboratoire de Toxicologie Environnementale, INRA, UR 406

Abeilles \& Environnement, Site Agroparc, 84000 Avignon, France

J. M. Bonmatin

Centre de Biophysique Moléculaire, UPR 4301 CNRS, affiliated to

Orléans University and to INSERM, 45071 Orléans cedex 02, France

\section{A. Downs}

Haereticus Environmental Laboratory, P.O. Box 92, Clifford,

VA 24533, USA

D. Goulson

School of Life Sciences, University of Sussex, Sussex BN1 9RH, UK

\section{P. Kreutzweiser}

Canadian Forest Service, Natural Resources Canada, 1219 Queen

Street East, Sault Ste Marie, ON P6A 2E5, Canada

\section{Krupke}

Department of Entomology, Purdue University, West Lafayette, IN, USA
Lepidoptera (butterflies and moths), Lumbricidae (earthworms), Apoidae sensu lato (bumblebees, solitary bees) and the section "other invertebrates" review available studies on the other terrestrial species. The sections on freshwater and marine species are rather short as little is known so far about the impact of neonicotinoid insecticides and fipronil on the diverse invertebrate fauna of these widely exposed habitats.

\section{Liess}

Department System-Ecotoxicology, Helmholtz Centre for Environmental Research, UFZ, Permoserstrasse 15, 04318 Leipzig, Germany

M. McField

Healthy Reefs for Healthy People Initiative, Smithsonian Institution, Belize City, Belize

\section{A. Morrissey}

Department of Biology and School of Environment and Sustainability, University of Saskatchewan, 112 Science Place, Saskatoon, SK S7N 5E2, Canada

D. A. Noome

Task Force on Systemic Pesticides, 46, Pertuis-du-Sault, 2000 Neuchâtel, Switzerland

D. A. Noome

Kijani, Kasungu National Park, Private Bag 151, Lilongwe, Malawi

\section{J. Settele $\cdot$ M. Wiemers}

Department of Community Ecology, Helmholtz-Centre for Environmental Research, UFZ, Theodor-Lieser-Str. 4, 06120 Halle, Germany

\section{J. Settele}

German Centre for Integrative Biodiversity Research (iDiv), Halle-Jena-Leipzig, Deutscher Platz 5e, 04103 Leipzig, Germany 
For terrestrial and aquatic invertebrate species, the known effects of neonicotinoid pesticides and fipronil are described ranging from organismal toxicology and behavioural effects to population-level effects. For earthworms, freshwater and marine species, the relation of findings to regulatory risk assessment is described. Neonicotinoid insecticides exhibit very high toxicity to a wide range of invertebrates, particularly insects, and field-realistic exposure is likely to result in both lethal and a broad range of important sublethal impacts. There is a major knowledge gap regarding impacts on the grand majority of invertebrates, many of which perform essential roles enabling healthy ecosystem functioning. The data on the few non-target species on which field tests have been performed are limited by major flaws in the outdated test protocols. Despite large knowledge gaps and uncertainties, enough knowledge exists to conclude that existing levels of pollution with neonicotinoids and fipronil resulting from presently authorized uses frequently exceed the lowest observed adverse effect concentrations and are thus likely to have large-scale and wide ranging negative biological and ecological impacts on a wide range of non-target invertebrates in terrestrial, aquatic, marine and benthic habitats.

Keywords Pesticides $\cdot$ Neonicotinoids $\cdot$ Fipronil $\cdot$ Non-target species · Invertebrates · Honeybee $\cdot$ Earthworms · Butterflies · Freshwater habitat $\cdot$ Marine habitat

\section{Introduction}

Neonicotinoids and fipronil are relatively new, widely used, systemic compounds designed as plant protection products to kill insects which cause damage to crops. They are also used in veterinary medicine to control parasites such as fleas, ticks and worms on domesticated animals and as pesticides to control non-agricultural pests. Other papers in this special issue have shown that neonicotinoid insecticides and fipronil

\footnotetext{
N. Simon-Delso

Beekeeping Research and Information Centre (CARI), Place Croix du Sud 4, 1348 Louvain-la-Neuve, Belgium

J. D. Stark

Puyallup Research and Extension Centre, Washington State

University, Puyallup, WA 98371, USA

J. P. Van der Sluijs

Centre for the Study of the Sciences and the Humanities, University of Bergen, Postboks 7805, 5020 Bergen, Norway

H. Van Dyck

Behavioural Ecology and Conservation Group, Biodiversity

Research Centre, Earth and Life Institute, Université Catholique de Louvain (UCL), Croix du Sud 4-5, bte L7.07.04,

1348 Louvain-la-Neuve, Belgium
}

are presently used on a very large scale (e.g. Simon-Delso et al. 2014, this issue), are highly persistent in soils, tend to accumulate in soils and sediments, have a high runoff and leaching potential to surface and groundwater and have been detected frequently in the global environment (Bonmatin et al. 2014, this issue). Effects of exposure to the large-scale pollution with these neurotoxic chemicals on non-target insects and possibly other invertebrates can be expected as identified for other insecticides. However, for the majority of insect and other invertebrate species that are likely to be exposed to neonicotinoids and fipronil in agricultural or (semi)natural ecosystems, no or very little information is available about the impact of these pesticides on their biology. Here we assess the present state of knowledge on effects on terrestrial and aquatic invertebrates.

\section{Terrestrial invertebrates}

\section{Honeybees}

Many studies have focused on investigating the effects of neonicotinoids and fipronil on honeybees (Apis mellifera). Apart from its cultural and honey production value, the honeybee is the most tractable pollinator species and critical for the production of many of the world's most important crops (Klein et al. 2007; Breeze et al. 2011). Losses of honeybees are generally measured as winter loss on national to regional level, and indications are that honeybee populations undergo high losses in many parts of the world (Oldroyd 2007; Stokstad 2007; van Engelsdorp and Meixner 2010; Van der Zee et al. 2012a, b).

No single cause for high losses has been identified, and high losses are associated with multiple factors including pesticides, habitat loss, pathogens, parasites and environmental factors (Decourtye et al. 2010; Mani et al. 2010; Neumann and Carreck 2010; Kluser et al. 2011). Apart from direct biotic and abiotic factors, changes in honeybee populations also depend on the economic value of honeybees and thus on human effort (Aizen and Harder 2009; Mani et al. 2010). Neonicotinoids are among the most used insecticides worldwide and are thus prime targets for investigating possible relationships with high honeybee losses.

\section{Acute and chronic lethal toxicity to honeybees}

Neonicotinoids and fipronil show high acute toxicity to honeybees (Table 1). The neonicotinoid family includes imidacloprid, clothianidin and thiamethoxam (the latter is metabolized to clothianidin in the plant and in the insect). Imidacloprid, clothianidin and thiamethoxam belong to the nitro-containing neonicotinoids, a group that is generally more toxic than the cyano-containing neonicotinoids, which includes acetamiprid and thiacloprid. Although neonicotinoids 
Table 1 Toxicity of insecticides to honeybees, compared to DDT. Dose used is given in gram per hectare, median lethal dose $\left(L D_{50}\right)$ is given in nanogram per bee. The final column expresses toxicity relative to DDT (DDT is 1). Source: Bonmatin (2011)

\begin{tabular}{|c|c|c|c|c|c|}
\hline Pesticide & ${ }^{\circledR}$ Example & Main use & $\begin{array}{l}\text { Typical dose } \\
\text { (g/ha) }\end{array}$ & $\begin{array}{l}\text { Acute } \mathrm{LD}_{50} \\
\text { (ng/bee) }\end{array}$ & $\begin{array}{l}\text { Ratio of } \mathrm{LD}_{50} \text { as } \\
\text { compared to DDT }\end{array}$ \\
\hline DDT & Dinocide & Insecticide & $200-600$ & 27,000 & 1 \\
\hline Thiacloprid & Proteus & Insecticide & 62.5 & 12,600 & 2.1 \\
\hline Amitraz & Apivar & Acaricide & - & 12,000 & 2.3 \\
\hline Acetamiprid & Supreme & Insecticide & $30-150$ & 7,100 & 3.8 \\
\hline Coumaphos & Perizin & Acaricide & - & 3,000 & 9 \\
\hline Methiocarb & Mesurol & Insecticide & $150-2,200$ & 230 & 117 \\
\hline Tau-fluvalinate & Apistan & Acaricide & - & 200 & 135 \\
\hline Carbofuran & Curater & Insecticide & 600 & 160 & 169 \\
\hline$\Lambda$-cyhalotrin & Karate & Insecticide & 150 & 38 & 711 \\
\hline Thiametoxam & Cruiser & Insecticide & 69 & 5 & 5,400 \\
\hline Fipronil & Regent & Insecticide & 50 & 4.2 & 6,475 \\
\hline Imidacloprid & Gaucho & Insecticide & 75 & 3.7 & 7,297 \\
\hline Clothianidin & Poncho & Insecticide & 50 & 2.5 & 10,800 \\
\hline Deltamethrin & Decis & Insecticide & 7.5 & 2.5 & 10,800 \\
\hline
\end{tabular}

are applied as foliar insecticides with possible direct exposure risks to honeybees, a large part of neonicotinoid use consists of seed coating or root drench application. Fipronil belongs to the phenylpyrazole family of pesticides and, like the neonicotinoids, has systemic properties (Simon-Delso et al. 2014).

Given that neonicotinoids and fipronil act systemically in plants, oral lethal doses for honeybees have been extensively studied for these compounds. Unlike many older classes of insecticides, neonicotinoids may be more toxic when ingested (Suchail et al. 2001; Iwasa et al. 2004). The level of neonicotinoids and fipronil that honeybees are exposed to in the nectar and pollen of treated plants varies greatly, although there are trends based upon application method. Generally, soil drenches and foliar application result in higher concentrations of the active compounds in plants than seed treatments, with the latter application used in large, annual cropping systems like grain crops, cotton and oilseed crops.

In practice, the honeybee lethal dose $50\left(\mathrm{LD}_{50}\right)$ for these pesticides varies for a wide range of biotic and abiotic conditions. The $\mathrm{LD}_{50}$ of imidacloprid, for example, has shown values between 3.7 and 40.9, 40 and 60, 49 and 102 and 490 ng/bee (Nauen et al. 2001; Schmuck et al. 2001; Suchail et al. 2001; DEFRA 2007, 2009). This variation, of a factor 100 (5-500 ng/bee), has been observed not only between colonies but also among bees taken from a single colony. A major component of this observed variation likely stems from the discrepancy in the contact and oral toxicities of these compounds, with contact lethal doses generally being higher than oral lethal doses. However, contact with the floral parts is frequent when the bees visit flowers, and this is different from the topical application used in laboratory conditions.

Other sources of variability may be attributed to differences in environmental conditions during testing as well as any inherent differences in the condition of the tested bees themselves. For example, data have shown that measured $\mathrm{LD}_{50}$ values for bees vary with temperature (Medrzycki et al. 2011), the age of bees (Schmuck 2004; Medrzycki et al. 2011), the honeybee subspecies tested (Suchail et al. 2000), the pattern of exposure (Illarionov 1991; Belzunces 2006) and prior exposure of bees to pesticides (Belzunces 2006). Given the large variability of honeybee toxicity data, it has been suggested that $\mathrm{LD}_{50}$ values should only be used to compare levels of toxicity among pesticides rather than drawing conclusions about the risk of mortality posed to honeybees via environmental exposure to pesticides (Belzunces 2006).

Oral subchronic exposure to imidacloprid and six of its metabolites induced a high toxicity at concentrations of $0.1,1$ and $10 \mathrm{ppb}$ (part per billion) or $\mathrm{ng} / \mathrm{g}$, whereas the metabolites olefin-imidacloprid and 5-OH-imidacloprid were toxic in acute exposure. The main feature of subchronic toxicity is the absence of a clear dose-effect relationship that can account for a maximum effect of the lowest concentration due to the existence of multiple molecular targets, as has been demonstrated in the honeybee (Déglise et al. 2002; Thany et al. 2003; Thany and Gauthier 2005; Barbara et al. 2008; Gauthier 2010; Dupuis et al. 2011; Bordereau-Dubois et al. 2012). The absence of clear dose-effect relationships has also been observed in other studies, at higher concentrations (Schmuck 2004).

Existence of non-monotonic dose-response relations implies that some chemicals, including neonicotinoids, 
have unexpected and potent effects at (very) low doses. These non-linear and often non-intuitive patterns are due to the complex interplay of receptor binding and gene reprogramming effects of such substances and can generate unexpected dose-response relationships, many of which are still being mapped out (Fagin 2012; Charpentier et al. 2014). This poses major challenges to risk assessment based on the classical log-probit model.

As previously reviewed by van der Sluijs et al. (2013), there are no standardised protocols for measuring chronic lethal effects. In traditional risk assessment of pesticides, they are usually expressed in three ways: $\mathrm{LD}_{50}$ : the dose at which $50 \%$ of the exposed honeybees die (usually within a 10 day time span); no observed effect concentration (NOEC): the highest concentration of a pesticide producing no observed effect; and lowest observed effect concentration (LOEC): the lowest concentration of a pesticide producing an observed effect.

For imidacloprid, including its neurotoxic metabolites, lethal toxicity can increase up to 100,000 times compared to acute toxicity when the exposure is extended in time (Suchail et al. 2001). There has been some controversy on the findings of that study, which are discussed in detail by Maxim and Van der Sluijs $(2007,2013)$. However, the key finding that exposure time amplifies the toxicity of imidacloprid is consistent with later findings, implying that the standard 10 day chronic toxicity test for bees is far too short for testing neonicotinoids and fipronil, given their persistence and hence the likely chronic exposure of bees under field conditions. Indeed, honeybees fed with $10^{-1}$ of the $\mathrm{LC}_{50}$ of thiamethoxam showed a $41.2 \%$ reduction of life span (Oliveira et al. 2013). Recent studies have shown that chronic toxicity of neonicotinoids can more adequately be expressed by time to $50 \%$ mortality instead of by the 10 day $\mathrm{LD}_{50}$ (Sánchez-Bayo 2009; Maus and Nauen 2010; Tennekes 2010; Tennekes 2011; Tennekes and Sánchez-Bayo 2012; Mason et al. 2013; Rondeau et al. 2014). There is a linear relation between the logarithm of the daily dose and the logarithm of the time to $50 \%$ mortality (Tennekes 2010, 2011; Tennekes and Sánchez-Bayo 2012; Tennekes and Sánchez-Bayo 2013; Rondeau et al. 2014). Sanchez-Bayo and Goka (2014) demonstrated that fieldrealistic residues of neonicotinoid insecticides in pollen pose high risk to honeybees and bumblebees, whilst in the field synergisms with ergosterol inhibiting fungicides will further amplify these risks. They found that imidacloprid poses the highest risk to bumblebees (31.8-49\% probability to reach the median lethal cumulative dose after 2 days feeding on field-realistic dose in pollen) and thiamethoxam the highest risk to honeybees (3.7-29.6\% probability to reach median lethal cumulative dose). In experiments with honeybee colonies, similar, long-term chronic effects have been found with typical times of 80-120 days for $1 \mathrm{ppm}$ dinotefuran and $400 \mathrm{ppb}$ clothianidin (Yamada et al. 2012). Note that these studies used concentrations that are on the uppermost limit of the currently reported ranges of concentrations found in pollen and nectar in the field. However, such data are sparse and limited to a few crops only, so it cannot yet be concluded whether such concentrations are rare or common in the fieldthe question of "field-relevant dose" is not yet fully resolved, and it is likely that there is a wide range in these values over space and time (Van der Sluijs et al. 2013).

Field and laboratory studies attempting to test field-realistic lethal doses have shown variable, often conflicting, results. In one study, chronic oral and contact exposure during 10 11 days to $1 \mu \mathrm{g} / \mathrm{bee}$ of acetamiprid and $1,000 \mu \mathrm{g} / \mathrm{bee}$ of thiamethoxam caused no significant worker mortality (Aliouane et al. 2009). Conversely, laboratory studies using imidacloprid showed high worker mortality when honeybees consumed contaminated pollen (40 ppb) (Decourtye et al. $2003,2005)$ and contaminated sugar syrup $(0.1,1.0$ and $10 \mathrm{ppb}$ ) (Suchail et al. 2001). These results were contrary to those of field studies performed by Schmuck et al. (2001), who reported no increased worker mortality when colonies were exposed to sunflower nectar contaminated with imidacloprid at rates from 2.0 to $20 \mu \mathrm{g} / \mathrm{kg}$. Faucon et al. (2005) also found no worker mortality in a field study of honeybees fed imidacloprid in sugar syrup. A meta-analysis by Cresswell (2011) concluded that oral exposure to imidacloprid at realistic field concentrations did not result in worker mortality, although a subsequent study by Yamada et al. (2012) feeding a range of dinotefuran (1-10 ppm) and clothianidin (0.4-4 ppm) concentrations demonstrated colony failure within 104 days in each case, suggesting that detection of colony-level effects may require longer post-exposure observation.

Field studies to investigate the exposure of bees to pesticides face major difficulties. For the analysis of very low concentrations of compounds present in pollen, nectar, bees or other matrices, appropriate methods that meet validity criteria of quantitative analysis have to be developed. Pilling et al. (2013) exposed bees to thiamethoxam-treated maize and oilseed rape but were not able to quantify concentrations lower than $1 \mathrm{ppb}$, although this may be a result of the authors using a lower seed treatment application than is used in normal agricultural practice. Even though both treatment and control colonies experienced relatively high losses (mostly queens laying only drone brood) and the authors were unable to undertake any statistical analysis due to a lack of replication, they wrongly concluded that there is a low risk to honeybees from exposure to treated maize and oilseed rape.

Also, in terms of activity and feeding behaviour, bees might not be foraging on treated crops in (exactly) the same way as they would do on untreated crops (Colin et al. 2004). Furthermore, comparison of treated and control areas can be totally flawed because control fields might not be "clean" but treated with other pesticides, 
including insecticides. The recent study of Pilling and coworkers on thiamethoxam (Pilling et al. 2013) is illustrative for this case as it did not provide information about the treatment status of the control plots.

For mass-dying of bees in spring near corn fields during sowing of neonicotinoid-treated seeds, there now is a one to one proven causal link. Acute intoxication occurs through exposure to the dust cloud around the pneumatic sowing machines during foraging flights to adjacent forests (providing honeydew) or nearby flowering fields (Apenet 2010; Girolami et al. 2012; Tapparo et al. 2012; Krupke et al. 2012; Pochi et al. 2012; Tapparo et al. 2012). In these cases, dead bees have typically been found to have high levels of seed treatment neonicotinoids on, or in, their bodies. Such mass colony losses during corn sowing have been documented in Italy, Germany, Austria, Slovenia, the USA and Canada (Gross 2008; Krupke et al. 2012; Sgolastra et al. 2012; Tapparo et al. 2012). In response to the incidents, the adherence of the seed coating has been improved owing to better regulations, and an improved sowing technique has recently become compulsory throughout Europe (European Commission 2010). However, despite the deployment of air deflectors in the drilling machines and improved seed coating techniques, emissions are still substantial and the dust cloud remains acutely toxic to bees (Biocca et al. 2011; Marzaro et al. 2011; Girolami et al. 2012; Tapparo et al. 2012; Sgolastra et al. 2012).

Acute lethal effects of neonicotinoids dispersed as particles in the air seem to be promoted by high environmental humidity (Girolami et al. 2012). Honeybees also transport toxic dust particles on their bodies into the hive (Girolami et al. 2012). Sunny and warm days also seem to favour the dispersal of active substances (Greatti et al. 2003).

\section{Sublethal effects on honeybees}

Effects on activity, locomotion, metabolism and ontogenetic development Imidacloprid, thiamethoxam and clothianidin have been shown to rapidly induce flight muscle paralysis in honeybees exposed to guttation drops containing these substances, resulting in the cessation of wing movements (Girolami et al. 2009). Imidacloprid further impairs the mobility of bees, as reflected by decreases in running and walking and increases in the time that exposed bees remain stationary (Medrzycki et al. 2003). However, when exposed to subchronic doses of neonicotinoids, decreases in locomotion were not observed in honeybees and bumblebees by Cresswell et al. (2012b).

Ontogenetic development is a crucial period that determines the physiological and functional integrity of adult individuals. Thus, in addition to the effects on adults, neonicotinoids may act on larval development with consequences for the adult stage. Adult honeybees exposed to imidacloprid during the larval stage exhibit impairment of olfactory associative behaviour (Yang et al. 2012). This could be due to altered neural development. Impairments in mushroom body development in the bee brain and the walking behaviour of honeybee workers have been observed in individuals exposed to imidacloprid during the larval period (Tomé et al. 2012). Effects on adult bees exposed during the larval stage could also be attributed to the induction of cell death by imidacloprid in larvae (Gregorc and Ellis 2011). In the early stages of adult life, after emergence, imidacloprid can disrupt the development of hypopharyngeal glands by decreasing the size of the acini and by increasing the expression of hsp70 and hsp 90 (Smodis Skerl et al. 2009; Hatjina et al. 2013). Derecka et al. (2013) provided beehives in the field for 15 days with syrup tainted with $2 \mu \mathrm{g} / \mathrm{l}$ imidaclopid. They found that these levels of imidacloprid, at the low end of the field-realistic range, significantly impact energy metabolism in worker bee larvae.

Impacts of pesticides on metabolism may affect the detoxifying, intermediary and energetic metabolism pathways. Imidacloprid impairs brain metabolism in the honeybee which results in an increase of cytochrome oxidase in mushroom bodies (Decourtye et al. 2004a, b).

Effects on behaviour, learning and memory Optimal function of the honeybee nervous system is critical to individual and colony functioning (Desneux et al. 2007; Thompson and Maus 2007). Increasing levels of research effort have been devoted to developing an improved understanding of how sublethal exposure to neonicotinoids and fipronil may affect the honeybee nervous system. There is evidence that sublethal exposure can affect learning, memory and orientation in honeybees.

Laboratory experiments administering a single dose of imidacloprid demonstrated that learning was altered (Guez et al. 2001; Lambin et al. 2001), and exposure to chronic sublethal doses has demonstrated that learning and foraging are impaired by imidacloprid and fipronil (Decourtye et al. 2003). Furthermore, thiamethoxam has been shown to decrease memory capacity (Aliouane et al. 2009). The methodologies and doses varied in these laboratory tests, but all used concentrations above $20 \mathrm{ppb}$; this is towards the upper end of concentrations found in most field situations. These concentrations would not be expected to be found in pollen or nectar following seed treatment applications, but have been found in cucurbit flowers following soil drench applications (Dively and Hooks 2010). Field experiments offer the potential for powerful tests; however, results have been mixed, and many studies focus on honeybee orientation to and from a feeding source. A study that trained honeybee foragers to a sugar syrup reward in a complex maze demonstrated that $38 \%$ of bees found the food source following ingestion of $3 \mathrm{ng} / \mathrm{bee}$ of 
thiamethoxam, compared with $61 \%$ in an unexposed control group (Decourtye and Devillers 2010). A series of studies training foragers to orient to a sugar feeder found that foragers were unable to return to the hive after ingesting imidacloprid at concentrations ranging from 100 to $1,000 \mathrm{ppb}$ (Bortolotti et al. 2003; Ramirez-Romero et al. 2005; Yang et al. 2008). In contrast, other semi-field studies have shown no effects upon foraging or survivorship following exposure to canola, maize and sunflowers grown from neonicotinoid-treated seeds (Schmuck et al. 2001; Cutler and Scott-Dupree 2007; Nguyen et al. 2009). Possible explanations for these conflicting results may be that when given a range of foraging opportunities, honeybees may reduce foraging visits to food sources containing pesticides (Mayer and Lunden 1997; Colin et al. 2004), or that neonicotinoids do not have effects on colonies in the exposure regimes tested here.

Recently, Henry et al. (2012a, b) described the results of innovative field experiments using radio frequency identification (RFID) tags to determine the colony-level effects of orientation impairment upon foragers fed a sublethal dose of imidacloprid (1.42 $\mathrm{ng}$ in $20 \mu \mathrm{l}$ of sucrose syrup). In two separate experiments, treated foragers failed to return to the colony at rates of 10.2 and $31.6 \%$, relative to untreated foragers feeding upon the same flowering plants. A higher risk of not returning was associated with the more difficult orientation tasks. Using these forager loss rates, the researchers modelled the colony-level effects and found significant, largely consistent deviations from normal colony growth rates, in some cases to levels that may put the colony at risk of collapse. A subsequent suggestion by Cresswell and Thompson (2012) to alter the simulation slightly to reflect the period when seed-treated crops are flowering demonstrated that the risk of collapse was no longer evident. However, a follow-up calculation by Henry et al. (2012a) using a larger dataset that incorporated a range of empirically derived colony growth estimates revealed even higher deviations from normal than the original work: a more serious negative outcome for colonies. The variable outcomes based upon model assumptions reflect uncertainties that have plagued honeybee researchers and further underscore the importance of ensuring that models are robust and represent a range of scenarios. The key contribution of this work was the demonstration that sublethal doses can impose a stressor (i.e. non-returning foragers) that can have significant negative outcomes on a colony level.

Learning and memory represent fundamental functions involved in the interaction of individuals with their environment and are critical in enabling bees to respond to the requirements of the colony throughout their life. Imidacloprid impairs learning and olfactory performance via both acute and chronic exposure pathways, and summer bees appear more sensitive than winter bees (Decourtye et al. 2003). These effects are observed not only in the laboratory but also in semi-field conditions, and bees do not recover after exposure ceases. Results obtained with acetamiprid and thiamethoxam showed that the action of neonicotinoids depends on the level/ degree of exposure and cannot be generalized to structurally related compounds. Unlike contact exposure, oral exposure of acetamiprid resulted in an impairing of long-term retention of olfactory learning (El Hassani et al. 2008). Conversely, for thiamethoxam, subchronic exposure, but not acute exposure, elicited a decrease of olfactory memory and an impairment of learning performance (El Hassani et al. 2008; Aliouane et al. 2009).

Neonicotinoids have specific routes of metabolism in insects, particularly in the honeybee, that lead to complex influences on learning and memory processes. Imidacloprid and thiamethoxam are metabolized into toxic metabolites that may potentially bind to different honeybee nicotinic acetylcholine receptors (Nauen et al. 2001; Suchail et al. 2001, 2004a; Nauen et al. 2003; Ford and Casida 2006; Benzidane et al. 2010; Casida 2011). The metabolism of acetamiprid results in the appearance of different metabolites in the honeybee, among which 6-chloronicotinic acid is toxic in chronic exposure but not in acute exposure and remains stable for at least $72 \mathrm{~h}$, especially in the head and the thorax (Suchail et al. 2001, 2004a; Brunet et al. 2005). Considering the presence of multiple active metabolites over time, it is very difficult to ascertain what steps of the memory process (acquisition, consolidation or retrieval) are affected by imidacloprid, acetamiprid, thiamethoxam or their metabolites.

Habituation may be defined as "a form of learning that consists in the gradual and relatively prolonged decrease of the intensity or the frequency of a response following the repeated or prolonged stimulus responsible for eliciting such a response" (Braun and Bicker 1992; Epstein et al. 2011a, b; Belzunces et al. 2012). Habituation can be regarded as an important adaptive behaviour because it allows individuals to minimize their response and, therefore, their energy investment, towards unimportant stimuli. The neonicotinoid imidacloprid alters patterns of habituation in honeybees following contact exposure to a sublethal dose (Guez et al. 2001; Lambin et al. 2001). Imidacloprid-induced changes in habituation appear to vary depending on the age of bees and time after exposure. Furthermore, these changes in habituation may be due to factors such as differential sensitivity of different nicotinic acetylcholine receptors (nAChRs) to imidacloprid (Déglise et al. 2002; Thany et al. 2003; Thany and Gauthier 2005; Barbara et al. 2008; Gauthier 2010; Dupuis et al. 2011; Bordereau-Dubois et al. 2012; Farooqui 2013), or the accumulation of imidacloprid metabolites like olefin and 5-hydroxy-imidacloprid, which can delay or accelerate habituation, respectively (Guez et al. 2001, 2003).

Olfaction and taste are very important physiological senses for honeybees (Detzel and Wink 1993; Giurfa 1993; Balderrama et al. 1996; Goulson et al. 2001; Reinhard et al. 
2004; Gawleta et al. 2005; Couvillon et al. 2010; Maisonnasse et al. 2010; Kather et al. 2011). The effects of neonicotinoids on gustation can be explored by studying the modulation of the gustatory threshold, which can be defined as the lowest concentration of a sucrose solution applied to the antenna that triggers a feeding response. Different active compounds have been shown to induce dissimilar effects on gustation in honeybees. For example, fipronil increases the gustatory threshold of bees subjected to contact exposure (El Hassani et al. 2005). Whilst similar results were found for imidacloprid, acetamiprid decreases the threshold of bees that are exposed orally, but not topically (El Hassani et al. 2009). Thiamethoxam elicits a decrease in honeybee responsiveness to sucrose, and exposure to acetamiprid increases the responsiveness of honeybees to water regardless of exposure route (El Hassani et al. 2008; Aliouane et al. 2009).

The discrepancy in the effects observed could be explained in part by neonicotinoid metabolism that induced the appearance of toxic metabolites (Suchail et al. 2004a, b; Brunet et al. 2005) and by the existence of different nAChRs that are either sensitive and resistant to particular neonicotinoids (Déglise et al. 2002; Thany et al. 2003; Thany and Gauthier 2005; Barbara et al. 2008; Gauthier 2010; Dupuis et al. 2011; Bordereau-Dubois et al. 2012). Although it has been demonstrated in pollinating flies and in beetles, the repellent effect of imidacloprid and other neonicotinoids has not been investigated in the honeybee (Easton and Goulson 2013).

Accurate navigation is essential for efficient foraging and, hence, for colony health and survival. Neonicotinoids and fipronil may impair navigation in different ways. Sublethal exposure of honeybees to clothianidin and imidacloprid elicits a decrease in foraging activity and induces longer foraging flights (Schneider et al. 2012). Thiamethoxam induces high mortality by causing failure in the homing behaviour of foraging bees, leading to large losses of foragers from the colony (Henry et al. 2012a, b). Although this effect has been demonstrated for the pyrethroid deltamethrin for almost 20 years (Vandame et al. 1995), impacts on the homing behaviour of foraging bees continue to be left out of the assessment process for pesticide registration.

Proper foraging behaviour is essential for both individual bees and the colony as a whole because it determines the availability of food (stores) and, consequently, the survival of the colony. Exposure to imidacloprid, clothianidin and fipronil can lead to reductions in the proportion of active bees in the hive and, furthermore, initiate behaviours that can reduce the efficiency of foraging flights. For example, exposed individuals may spend longer periods of time at a food source, decrease the frequency of visits, increase the time between foraging trips, engage in longer foraging flights, reduce foraging distances, exhibit problems revisiting the same feeding site or exhibit reductions in visual learning capacities (Nielsen et al. 2000; Morandin and Winston 2003;
Colin et al. 2004; Ramirez-Romero et al. 2005; Yang et al. 2008; Han et al. 2010; Schneider et al. 2012; Teeters et al. 2012). Fischer et al. (2014) exposed adult honeybees to sublethal doses of imidacloprid (7.5 and $11.25 \mathrm{ng} / \mathrm{bee}$ ), clothianidin $(2.5 \mathrm{ng} / \mathrm{bee})$ and thiacloprid $(1.25 \mu \mathrm{g} / \mathrm{bee})$ and subsequently tracked the flight paths of individual bees with harmonic radar. The rate of successful return was significantly lower in treated bees, the probability of a correct turn at a salient landscape structure was reduced and less directed flights during homing flights were performed. These findings show that sublethal doses of these three neonicotinoids either block the retrieval of exploratory navigation memory or alter this form of navigation memory. Reproduction and colony development may be regarded as integrative endpoints for assessing the final impacts of pesticides on bees as both are a compulsory condition of social insect physiology.

Neonicotinoids such as thiacloprid, thiamethoxam and imidacloprid decrease brood production, larval eclosion, colony growth rate and the number of queens reared in bumblebees (Tasei et al. 2000; Mommaerts et al. 2010; Whitehorn et al. 2012). Studies suggest that the reduction in brood production may be associated with a reduction in pollen and sugar consumption by adult bees (Laycock et al. 2012a, b). The rearing of honeybees on brood comb containing high levels of pesticide residues results in delayed larval development and emergence and shortened adult longevity (Wu et al. 2011). Since the brood combs in the latter study contained five neonicotinoids at relatively high concentrations, it is difficult to ascribe the observed effects to any one pesticide, or pesticide class. An epidemiological study involving Hill's criteria (minimal conditions that prove evidence of a causal relationship) revealed conflicting results on the involvement of dietary traces of neonicotinoids in the decline of honeybee populations (Cresswell et al. 2012a) and could not establish a causal link between observations of bee decline and neonicotinoid use rates.

\section{Interaction with pathogens}

Detrimental effects of pesticides might be increased in combination with other environmental stress agents (Mason et al. 2013). Specific pathogens and parasites are ancestral companions of (some) honeybee populations, and accidental movement of parasites and pathogens by man has exposed both honeybees and wild bees to non-native enemies to which they may have reduced resistance (e.g. Goulson 2003; Graystock et al. 2013a, b). Imidacloprid can act synergistically with the pathogen Nosema spp. by increasing Nosema-induced mortality (Alaux et al. 2010). It affects social immunity and so increases the number of Nosema spores in the guts of bees from imidacloprid-exposed colonies exposed in cage studies (Pettis et al. 2012). Sequential exposure to Nosema ceranae can sensitize bees to thiacloprid by eliciting potentiation that 
leads to high mortality rates, a feature shared with fipronil (Vidau et al. 2011; Aufauvre et al. 2012). Similarly, other experiments with fipronil and $N$. ceranae have demonstrated reciprocal sensitization (Aufauvre et al. 2012). Furthermore, exposure to pesticides during embryonic and post-embryonic development may alter the susceptibility of adult bees to pathogens. For example, adult honeybees reared in brood combs containing high levels of pesticide residues exhibit higher levels of infection by $N$. ceranae and higher levels of Nosema spores (Wu et al. 2012).

Di Prisco et al. (2013) demonstrated that clothianidin negatively modulates nuclear factor kappa-light-chain-enhancer of activated B cells (NF- $\mathrm{KB}$, a protein involved in DNA transcription) immune signaling in insects and adversely affects honeybee antiviral defences controlled by this transcription factor. They identified a negative modulator of NF- $\mathrm{KB}$ activation specific for insects. Exposure to clothianidin, by enhancing the transcription of the gene encoding this inhibitor, reduces immune defences and promotes the replication of the deformed wing virus present in honeybees. Similar immunosuppression was found to be induced by imidacloprid. The occurrence of this insecticide-induced viral proliferation at sublethal doses that are well within field-realistic concentrations suggests that the studied neonicotinoids are likely to have a negative effect under field conditions.

\section{Synergistic effects with other pesticides}

In agricultural ecosystems, honeybees are seldom exposed to only a single pesticide. Combined exposures could be of high concern because they can elicit synergies and potentiations. For example, thiacloprid acts synergistically with ergosterol biosynthesis inhibitor (EBI) fungicides in bees exposed in laboratory conditions but not in tunnel conditions (Schmuck et al. 2003).

Analyses of honeybees and colony contents indicate that honeybees are indeed frequently exposed to multiple pesticides simultaneously (Mullin et al. 2010; Krupke et al. 2012; Paradis et al. 2013). However, the study of pesticide mixtures can be challenging (Lydy et al. 2004), and there is a paucity of information in the literature regarding the mixtures encountered by honeybees. Triazole fungicides have been found in pollen collected from colonies (Krupke et al. 2012) and have been shown to synergize toxicity of some neonicotinoids (thiacloprid and acetamiprid) up to 559-fold in the laboratory, although the same results have not been shown in semi-field studies (Schmuck et al. 2003). Piperonyl butoxide also has been found in pollen and has been shown to synergize toxicity of some neonicotinoids (thiacloprid and acetamiprid) up to 244-fold in the laboratory (Iwasa et al. 2004). Despite the challenges associated with this type of research, this is a clear research gap that should be addressed in the future, given that honeybees rarely encounter only a single pesticide during foraging and/or in the hive.

Toxicity to bumblebees and solitary bees

Bumblebees (genus Bombus) are primitive social bees. Colonies start from overwintering queens, build up to a few hundred adult workers and break down when new queens and males are produced. A small number of bumblebee species are commercially reared for pollination, but many of the non-managed bumblebees also contribute substantially to crop pollination (Chagnon et al. 1993; Bosch and Kemp 2006; Greenleaf and Kremen 2006; Goulson 2010). Solitary bees that are also commonly managed in agricultural settings include the alfalfa leafcutter bee (Megachile rotundata), alkali bees (Nomia melanderi), blue orchard bees (Osmia lignaria) and Japanese horn-faced bees (Osmia cornifrons). M. rotundata is the major pollinator of alfalfa, which is grown as a high value livestock feed in North America. It is often considered a domesticated species, although populations frequently occur naturally. This species contributed US $\$ 5.26$ billion to the value of alfalfa hay in 2009 (Calderone 2012). In addition to managed bees, there are more than 20,000 species of wild bees in the world, many of which contribute to crop pollination, and all of them contribute to pollination of wild flowers.

There are few long-term population-level studies involving bumblebees and other bee species, and in many cases, the impacts of pesticide exposure and dosage are unclear. These species differ from honeybees in that they generally exhibit smaller foraging ranges and often prefer to nest in the ground. Therefore, populations located near agricultural operations and associated pesticide applications may have fewer alternative options for food and habitat resources. Furthermore, ground-nesting species may face additional exposure risks (i.e. pesticide-contaminated soil) that are not encountered by honeybees, but which remain to be evaluated. Finally, whilst bumblebees tend to be bigger, solitary bees are often smaller than honeybees; thus, these species likely receive a different dose relative to their body weight than honeybees do.

Likely levels of exposure of wild bee species are poorly understood. Whilst neonicotinoid levels have been quantified in the nectar and pollen of various crop plant species (Cresswell 2011; Anon 2012), the degree to which wild bees utilize these resources has not been measured, and furthermore, basic values of toxicity, such as $\mathrm{LD}_{50}$ and $\mathrm{LC}_{50}$, are completely lacking for the vast majority of these species. The few studies that do exist have employed a range of methods with conflicting results so that drawing general conclusions is difficult at this stage. Moreover, these studies are criticised for low sample size, which limits power to detect effects and/or highly unnatural laboratory conditions.

It is clear that neonicotinoids and fipronil are highly toxic to all bee species tested so far, which in addition to honeybees 
includes various Bombus species, several social stingless bee species and the solitary species $O$. lignaria and $M$. rotundata (Scott-Dupree et al. 2009; Valdovinos-Núñez et al. 2009; Gradish et al. 2010; Mommaerts et al. 2010; Tomé et al. 2012). Cresswell et al. (2012a, b) demonstrated that bumblebees exhibit sublethal responses to imidacloprid at $10 \mathrm{ppb}$, whilst honeybees were unaffected at this concentration. ScottDupree et al. (2009) found that O. lignaria is more sensitive to both clothianidin and imidacloprid than Bombus impatiens, with $M$. rotundata more sensitive still. Stark et al. (1995) found no difference in the $24 \mathrm{~h}$ contact $\mathrm{LD}_{50}$ of imidacloprid between honeybees and the solitary bee species $M$. rotundata and $N$. melanderi. Scott-Dupree et al. (2009) demonstrated that B. impatiens individuals were more tolerant of thiamethoxam and clothianidin than $O$. lignaria and $M$. rotundata. However, the orchard bee $O$. lignaria exhibits delayed hatching and development when fed imidacloprid at rates from 30 to $300 \mu \mathrm{g} / \mathrm{kg}$ (Abbott et al. 2008). Arena and Sgolastra (2014) compared the acute toxicity of numerous pesticides and found that Scaptotrigona postica and M. rotundata were more sensitive than honeybees to fipronil, whilst $N$. melanderi was more tolerant. Together, these results suggest that "other" bees may be at least as sensitive, if not more sensitive, to neonicotinoids than honeybees, although more work is clearly needed.

A number of studies have used queenless micro-colonies of bumblebees (containing only workers) to examine the sublethal effects of cumulative neonicotinoid exposure to low, field-realistic doses. Several have found no detectable effects; for example, Tasei et al. (2000) exposed Bombus terrestris micro-colonies to 6-25 ppb of imidacloprid and found no significant response. Similarly, Franklin et al. (2004) exposed B. impatiens to concentrations of up to $36 \mathrm{ppb}$ of clothianidin without detecting an impact (see also Morandin and Winston 2003). Most recently, Laycock et al. (2012a, b) exposed micro-colonies of $B$. terrestris to a range of concentrations of imidacloprid $(0-125 \mu \mathrm{g} / \mathrm{l})$ and detected a $30 \%$ reduction in fecundity at doses as low as $1 \mathrm{ppb}$. In the only comparable work on other bee species, Abbott et al. (2008) injected concentrations of up to $300 \mathrm{ppb}$ of neonicotinoids into pollen stores of $O$. lignaria and $M$. rotundata with no measurable impact on larval development.

Interestingly, negative effects seem to be detected more frequently and at lower concentrations when bees have to forage at a distance, even when the distances are tiny. Mommaerts et al. (2010) found no impact of imidacloprid exposure on micro-colonies of $B$. terrestris at field-realistic concentrations when food was provided in the nest, but when workers had to walk just $20 \mathrm{~cm}$ down a tube to gather food they found significant sublethal effects on foraging activity, with a median sublethal effect concentration $\left(\mathrm{EC}_{50}\right)$ of just $3.7 \mathrm{ppb}$. The same researchers also studied queenright colonies foraging in a glasshouse where food was $3 \mathrm{~m}$ from their nest and found that ingestion of $20 \mathrm{ppb}$ of imidacloprid caused significant worker mortality, including bees dying at the feeder. Significant mortality was also observed at $10 \mathrm{ppb}$, but not at $2 \mathrm{ppb}$. This may explain why some lab studies have failed to find effects.

With impacts more pronounced when bees have to leave the colony, one might predict more marked effects when bees are foraging naturally, travelling kilometres across the landscape (Knight et al. 2005; Osborne et al. 2008). Only four studies have examined impacts of exposure to neonicotinoids on non-Apis bees when free-flying in the landscape. Tasei et al. (2001) placed Bombus lucorum colonies in the field for 9 days, either adjacent to an imidacloprid-treated field or a control field of sunflowers. During this time, $54 \%$ more of the foragers from the ten imidacloprid-exposed colonies failed to return compared to the ten control colonies; however, this difference was not statistically significant as sample sizes were very small. After 9 days, the colonies were returned to the lab and fed ad libitum. Treated colonies grew more slowly but the difference was not significant. Gill et al. (2012) provided B. terrestris colonies with feeders containing $10 \mathrm{ppb}$ of imidacloprid in sugared water whilst simultaneously allowing bees freedom to forage outside the nest. Bees exposed to imidacloprid brought back pollen less often and tended to bring back smaller loads, compared to control bees. Feltham et al. (2014) simulated exposure of queenright $B$. terrestris colonies to a crop of flowering oilseed rape, providing them with sugared water and pollen containing 0.7 and $6 \mathrm{ppb}$ of imidacloprid, respectively, for 2 weeks. They found a $57 \%$ reduction in the mass of pollen brought back to colonies, which persisted for at least 4 weeks after treatment ceased. Only one study to date has attempted to examine the effects of exposure to neonicotinoids on colony-level development of bumblebees under field conditions; Whitehorn et al. (2012) used the same field-realistic doses as Feltham et al. (2014) and then allowed colonies to develop naturally in the field. They recorded significantly reduced nest growth and an $85 \%$ decrease in queen production in imidacloprid-exposed colonies compared to control colonies. This reduction in colony performance is likely due to a combination of factors such as reduced pollen input (as demonstrated by Gill et al. 2012 and Feltham et al. 2014) and perhaps impaired fecundity of queens (following Laycock et al. 2012a, b). In an 11 week greenhouse study, caged queenright colonies of $B$. impatiens were fed treatments of $0,10,20,50$ and $100 \mathrm{ppb}$ of imidacloprid, respectively, and clothianidin in sugar syrup $(50 \%)$ (Scholer and Krischik 2014). At 6 weeks, queen mortality was significantly higher in 50 and $100 \mathrm{ppb}$ and by 11 weeks in 20-100 ppb neonicotinyl-treated colonies. Starting at $20 \mathrm{ppb}$, there is a statistically significant reduction in queen survival (37\% for imidacloprid, $56 \%$ 
for clothianidin), worker movement, colony consumption and colony weight compared to $0 \mathrm{ppb}$ treatments. At $10 \mathrm{ppb}$ imidacloprid and $50 \mathrm{ppb}$ clothianidin, fewer males were produced (Scholer and Krischik 2014).

Bryden et al. (2013) conceived a model to simulate bumblebee colony development to assess the colony-level impacts of well-known sublethal effects on individuals. Their study shows that bumblebee colonies fail when exposed to sustained sublethal levels of pesticide. This is explained by impairment of colony function. Social bee colonies have a positive density dependence, and they are subject to an Allee effect. There is a critical stress level for the success of a colony such that a small increase in the level of stress can make the difference between failure and success.

It seems likely that intoxicated bees are fully able to gather food when it is presented to them within the nest, but when bees have to navigate over realistic distances to extract nectar and pollen from complex, patchily distributed flowers, the effects of intoxication become evident. Studies have focused mainly on behavioural effects in adult bees shortly after exposure to neonicotinoids, but there is evidence from both honeybees (Yang et al. 2012) and stingless bees (Tomé et al. 2012) that exposure during larval stages can impair development of the central nervous system and, hence, result in reduced adult performance several weeks after colony exposure. Therefore, the implications for risk assessment are clear; lab trials, and even trials where colonies are placed immediately adjacent to treated crops, are not appropriate for detecting these impacts. Similarly, experiments need to run for many weeks to examine the long-term effects of exposure on bee health.

The existing toxicological data suggests that impacts on diverse bee taxa are broadly similar at the level of the individual bee, with some evidence that bumblebees and solitary bees may be more susceptible than honeybees. It is clear that fieldrealistic doses of neonicotinoids can have a range of significant detrimental effects on larval development, adult fecundity, adult foraging behaviour and colony performance in social species. However, the effects of neonicotinoids on the vast majority of bee species have not been examined, and caution is necessary when extrapolating from social to solitary species. No studies have evaluated the impacts of neonicotinoids on solitary species under field conditions. It might plausibly be argued that the large colony size exhibited by honeybees and some stingless bees could buffer these species against reductions in foraging performance, as well as any navigational errors on the part of workers; however, this is unlikely to be the case for either bumblebee colonies, which have just a few hundred workers at most, or solitary bees, where a single female has sole responsibility for provisioning of offspring. Thus, impacts at the population level may be inversely related to levels of sociality. This possibility awaits experimental investigation.
Butterflies and moths (Lepidoptera)

Among agricultural practices, pesticide use is known to impact butterflies and moths; however, based on observational field data, it is difficult to distinguish the impacts of pesticides from other agricultural customs, such as fertilizer application or landscape simplification, e.g. by removal of hedgerows (Geiger et al. 2010). In the case of butterflies or moths that inhabit structures adjacent to areas where pesticides are applied via aerial spraying, indirect effects of drift from spraying may pose risks both during and after applications (Sinha et al. 1990). In the 1980s for example, helicopter application of pesticides in vineyards of the Mosel Valley in Germany nearly led to the extinction of an isolated population of the Apollo butterfly (Parnassius apollo) which was restricted to adjacent rocky slopes (Kinkler et al. 1987; Richarz et al. 1989; Schmidt 1997). In Northern Italy, butterfly communities in natural grasslands have suffered drastic declines downwind of intensively sprayed orchards, leading to the disappearance of all but the most generalist species (Tarmann 2009). Furthermore, spray applications of pesticides may alter soil quality (Freemark and Boutin 1995) and thereby indirectly affect the larvae and pupae of moth species residing in the upper layers of the soil surface during the spring.

Contrary to other non-target species (e.g. bees, birds, spiders, ground beetles), very few comparative pesticide sensitivity tests have been carried out for butterflies and moths. This is surprising given the significant role these insects play for conservation programs. One such study conducted by Brittain et al. (2010b) evaluated the impact of pesticides on various groups of pollinators. When comparing intensively managed systems (high pesticide application rates) with less intensively managed systems (fewer pesticide applications), the authors demonstrated that fewer bumblebee and butterfly species were observed in intensively managed habitat patches. The study also demonstrated that wild bees have higher pesticide-related risks than butterflies (Brittain et al. 2010b).

Moreover, studies by Feber et al. (1997) and Rundlöf et al. (2008) have demonstrated negative impacts of pesticides on butterflies. Both studies evaluated the impacts of organic versus conventional agriculture on butterfly populations. In each case, organic farms were found to host greater numbers and species of butterflies. This response was likely due in part to reduced applications of herbicides in organic systems, as herbicides reduce the abundance of host and nectar plants that are crucial for the survival of larvae as well as adults (Boggs 2003). In contrast, similar studies comparing Lepidopteran communities between organic and conventional agriculture systems found no differences in the number or species richness of butterflies (Weibull et al. 2000 and Brittain et al. 2010a). In the case of these studies, characteristics of the surrounding landscape such as the absence of specific vegetation 
elements (e.g. hedgerows or floral nectar sources) at both the local and regional scales, or the broad scale application of pesticides, may have influenced the outcome of the findings.

In contrast to the few ecological and ecotoxicological studies on the direct and indirect impacts of pesticides on nontarget Lepidoptera, numerous results are available on the impacts of pesticides on the butterfly and moth species that are regarded as agricultural pests during the larval stage (Haynes 1988; Davis et al. 1991a, b, 1993; Liang et al. 2003). The impacts of systemic pesticides on Lepidoptera have been investigated for some 32 pest species of moths in nine different families (Table 2). This represents a tiny fraction of the estimated 200,000 Lepidoptera species. The results demonstrate considerable variation in the impact of pesticides on different species of Lepidoptera. For example, Doffou et al. (2011a, b) noted that the susceptibility of two cotton pests, Pectinophora gossypiella (Gelechiidae) and Cryptophlebia leucotreta (Tortricidae), to acetamiprid differs almost 3-fold $\left(\mathrm{LD}_{50}=11,049\right.$ and 3,798 ppm, respectively). First instar Cydia pomonella caterpillars (Tortricidae) are more than 100 times as sensitive as final fifth instar caterpillars, with an $\mathrm{LC}_{50} /$ $\mathrm{LC}_{90}$ of $0.84 / 1.83$ and $114.78 / 462.11 \mathrm{ppm}$, respectively (Stara and Kocourek 2007a, b).

Not surprisingly, different neonicotinoid compounds vary in toxicity. Thiacloprid and acetamiprid for example are recorded to have stronger effects on the survival of Phyllonorycter ringoniella than all other neonicotinoid substances (Funayama and Ohsumi 2007a, b). Acetamiprid has been shown to be more toxic than thiacloprid in several studies, but the degree of difference varies greatly. For example, a study by Cichon et al. (2013) found thiacloprid to be two times as toxic to C. pomonella as acetamiprid $\left(\mathrm{LC}_{99} / \mathrm{LC}_{50}=\right.$ $1.55 / 0.17$ vs $0.71 / 0.08 \mathrm{ppm}$, respectively), whilst Magalhaes and Walgenbach (2011) recorded a 60-fold difference in the sensitivity of the same species to these compounds $\left(\mathrm{LC}_{50}=\right.$ 1.06 and $65.63 \mathrm{ppm}$, respectively).

Many studies have documented systemic pesticide resistance in Lepidoptera; for example, Phtorimaea operculella has been found to be resistant to fipronil (Doğramaci and Tingey 2007), Spodoptera litura to both fipronil and imidacloprid (Huang et al. 2006a, b; Ahmad et al. 2008; Abbas et al. 2012), C. pomonella to acetamiprid and thiacloprid (Cichon et al. 2013; Knight 2010; Stara and Kocourek 2007a, b), and Plutella xylostella to acetamiprid (Ninsin et al. 2000a, b). In the latter field study from Japan, an almost 10-fold higher dosage was required to reach the same lethal concentration $\left(\mathrm{LC}_{50} /_{95}=315 / 2,020\right.$ compared to 35.1/ $137 \mathrm{ppm}$ in susceptible laboratory colonies). Applications of such high concentrations may further increase negative impacts on non-target species of insects. Even low sublethal doses can have severe impacts on Lepidoptera populations. In a study on Helicoverpa armigera by Ahmad et al. (2013), a 16th of the $\mathrm{LC}_{50}$ of imidacloprid (5.38 ppm) increased the next generation survival rate by a factor of 4 (i.e. equivalent to $\mathrm{LC}_{10}$ ) compared to a treatment with the $\mathrm{LC}_{50}$ dose. Sublethal effects included a significant reduction in the survival and fecundity as well as increased mortality in the first and subsequent generations. Asaro and Creighton (2011a, b) noted that loblolly pines appeared to be protected from the Nantucket pine tip moth (Rhyacionia frustrana) even 1 year after treatment, and the treatment effect apparently was not confined to the target pest species, but extended to further nontarget insect species.

There is a clear need for studies on the impact of pesticides on butterflies and moths and in particular those species that are not agricultural pests, but which commonly inhabit managed landscapes. Extensive studies on the direct and indirect effects of pesticides on these non-target groups are urgently needed on different geographical scales and across long time periods (Aebischer 1990) and which include all developmental stages of butterflies and moths (i.e. egg, larva, pupa, adult). It is of paramount importance to include varying intensities of pesticide applications, their persistence and their interplay with biotic and abiotic factors (Longley and Sotherton 1997; Brittain et al. 2010b).

\section{Other invertebrates}

This section will review the studies on neonicotinoids and non-target organisms, in particular the predatory invertebrates of natural pest species. Biological pest control plays an important role in integrated pest management (Byrne and Toscano 2007; Peck and Olmstead 2010; Prabhaker et al. 2011; Khani et al. 2012) with studies suggesting that predators may contribute to the similarity in crop yields between nontreated and pesticide-treated fields (Albajes et al. 2003; Seagraves and Lundgren 2012).

\section{Routes of exposure}

Non-target organisms can be exposed to neonicotinoid pesticides in a variety of ways. Predatory invertebrates may become contaminated by consuming pests such as leafhoppers or aphids that feed on treated crops (Albajes et al. 2003; Papachristos and Milonas 2008; Moser and Obrycki 2009; Prabhaker et al. 2011; Khani et al. 2012). Direct contamination through the diet can also be a problem for other beneficial plant-feeding invertebrates (Dilling et al. 2009; Girolami et al. 2009; Moser and Obrycki 2009; Prabhaker et al. 2011; Khani et al. 2012). For example, several species of hoverfly and parasitoid wasps attack agricultural pests, but also subsidise their diet with nectar. Therefore, these insects can be affected by neonicotinoids, which are translocated into the nectar and pollen of treated crop plants (Stapel et al. 2000; Krischik et al. 2007). 


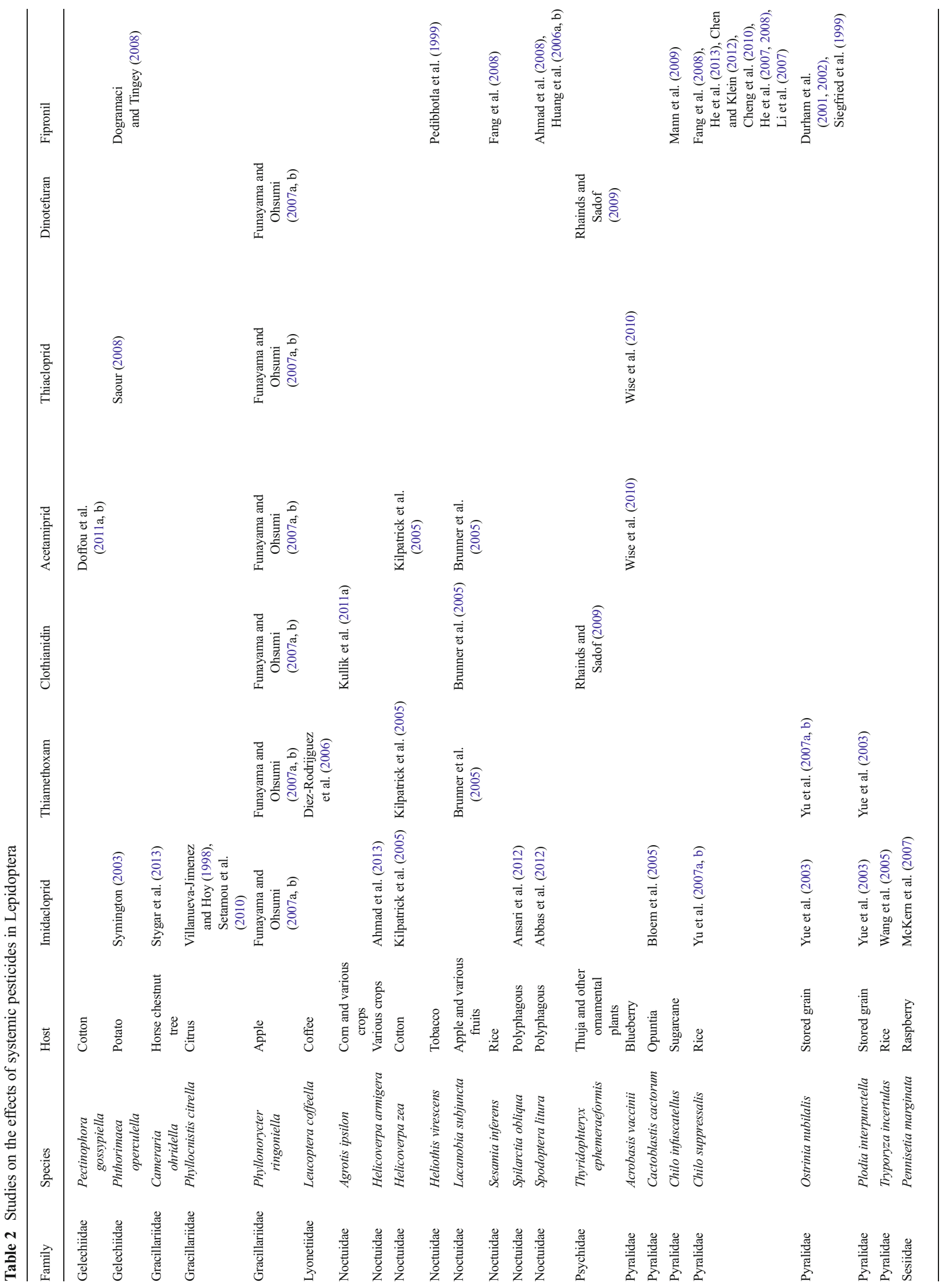




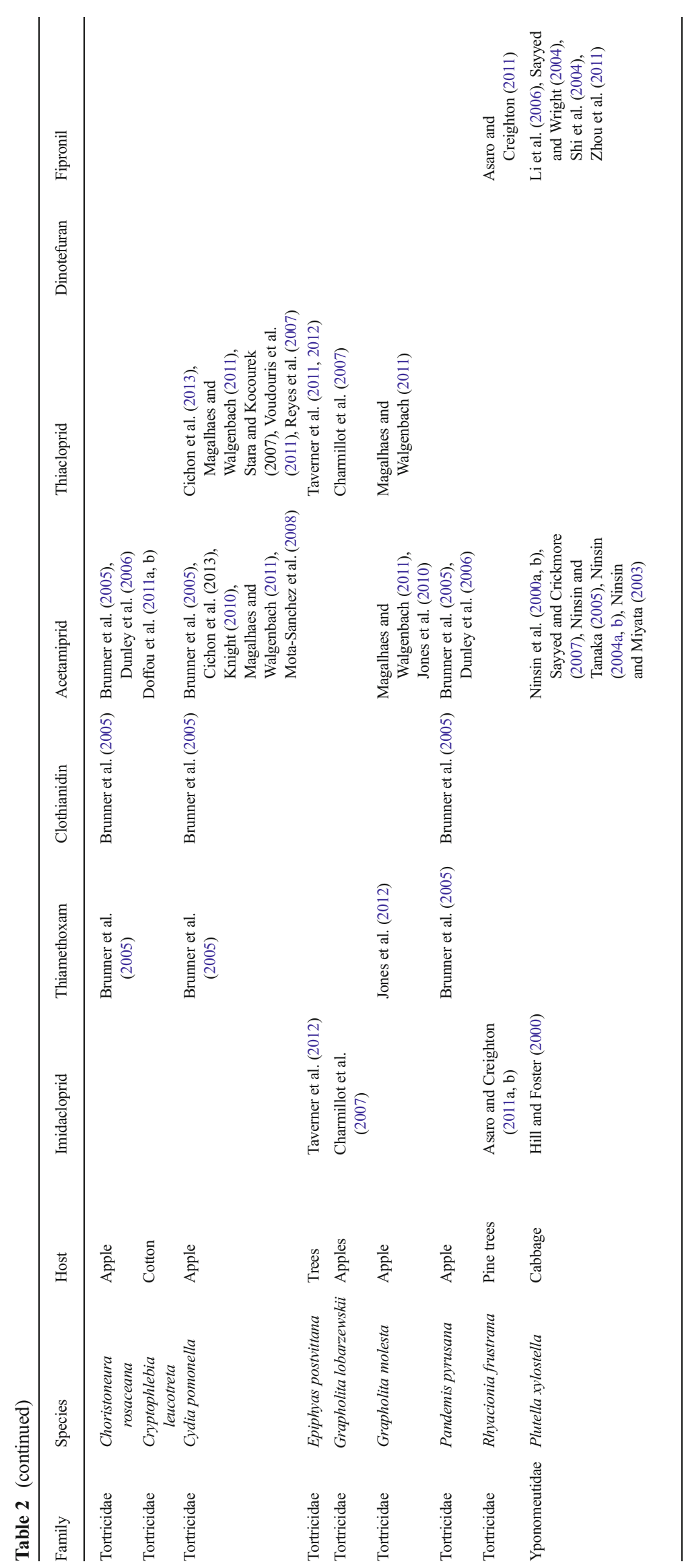


Other routes of exposure include contact with treated surfaces, exposure to sprays or consumption of guttation droplets (Papachristos and Milonas 2008; Prabhaker et al. 2011; Khani et al. 2012). For example, neonicotinoid soil drenches or injections have been found to adversely affect the development of Lepidoptera larvae pupating within the soil (Dilling et al. 2009), whilst soil drenches have been found to significantly lower the overall abundance of insect species and species richness. In one study, imidacloprid was used on eastern hemlock (Tsuga canadensis) to effectively control the hemlock woolly adelgid (Adelges tsugae); however, the abundance of non-target detrivorous, fungivorous and phytophagous invertebrates was significantly lower in soil drench and injection treatments, when compared to untreated plots (Dilling et al. 2009).

Parasitoid wasps such as Gonatocerus ashmeadi can come into contact with neonicotinoids when emerging from the eggs of its host. One such host, the glassy-winged sharpshooter (Homalodisca itripennis), a common agricultural pest of many different crops, lays its eggs on the underside of leaves, beneath the epidermal layer. If eggs are laid on neonicotinoidtreated plants, G. ashmeadi nymphs may be exposed to toxins when they emerge from the egg and chew through the leaf to get to the surface (Byrne and Toscano 2007).

A 3 year study by Peck (2009) found that when imidacloprid was used as a lawn treatment to target neonate white grubs (Coleoptera: Scarabaeidae), it exhibited cumulative detrimental effects on the abundance of Hexapods, Collembola, Thysanoptera and Coleoptera adults, which were suppressed by 54-62\% overall throughout the course of the study. Population numbers of non-target organisms can also be indirectly affected by a reduction in prey or host species (Byrne and Toscano 2007; Dilling et al. 2009).

\section{Diptera}

Of the Diptera, the genus Drosophila provides well-known and convenient model species for toxicity testing. Mechanisms of resistance to imidacloprid and its metabolism have been studied in Drosophila melanogaster. Particularly, cytochrome P450 monooxygenases (CYPs) are involved, as is the case in mosquitoes (Riaz et al. 2013). According to Kalajdzic et al. (2012), three P450 genes (Cyp4p2, Cyp6a2 and Cyp6g1) located on the $2 \mathrm{R}$ chromosome were highly up-regulated in imidacloprid-resistant flies. However, the same authors did not find that imidacloprid induced expression of Cyp6g 1 and Cyp6a2 (Kalajdzic et al. 2013). More recently, it has been shown that imidacloprid was metabolized to eight derivatives in D. melanogaster. In this process, only the P450 Cyp6g1 was involved in the enhanced metabolism in vivo (Hoi et al. 2014). Direct toxicity $\left(\mathrm{LC}_{50}\right)$ has been determined for various D. melanogaster strains. For instance, the toxicity of several neonicotinoids and butene-fipronil was evaluated (Arain et al. 2014) with neonicotinoids being less toxic than butenefipronil. It was suggested that differences exist between adults and larvae. Acute $\mathrm{LC}_{50}$ values can be compared to $\mathrm{LC}_{50}$ measured after chronic exposure, within two studies. With a mutant strain, Frantzios et al. (2008) found a decrease by a factor of 2 for adult flies (acute vs chronic) and a factor of 3 for larvae. Very recently, Charpentier and co-workers have distinguished between male and female flies, from a field strain (Charpentier et al. 2014). Here, the chronic LC $_{50}$ was 29 times lower than the acute $\mathrm{LC}_{50}$ for males; it was 172 times lower for females and 52 times lower for larvae. Additionally, this study demonstrated that a significant increase of mortality (27-28\%), with a V-shape, was occurring at concentrations 1,100 and 4,600 times lower than the chronic $\mathrm{LC}_{50}$ for males and females, respectively. Other parameters that are crucial for reproduction were tested (mating and fecundity). The LOEC was determined at a concentration that is 3,300,000 and more than 7,900,000 times lower than the acute $\mathrm{LC}_{50}$ for females and males, respectively. These data can be linked to data concerning mortalities observed by chronic exposure of bees at very low concentrations.

\section{Hymenoptera (excluding bees)}

A few studies have investigated the effect of neonicotinoid pesticides on parasitic wasps used as biological control agents. Stapel et al. (2000) found that the parasitoid wasp Microplitis croceipes had significantly reduced foraging ability and longevity after feeding on extrafloral nectar of cotton (Gossypium hirsutum) treated with imidacloprid. Prabhaker et al. (2007) give acute toxicity for two different exposure times for the parasitic wasp species Eretmocerus eremicus, Encarsia formosa, Aphytis melinus and G. ashmeadi (Table 3).
Table 3 Acute neonicotinoid toxicity for different Hymenoptera species (Prabhaker et al. 2007)

\begin{tabular}{|c|c|c|c|}
\hline \multirow[t]{2}{*}{ Species } & \multicolumn{2}{|c|}{$48 \mathrm{~h}$ exposure time $\mathrm{mg}(\mathrm{AI}) / \mathrm{ml}$} & \multirow{2}{*}{$\begin{array}{l}24 \mathrm{~h} \text { exposure time } \mathrm{mg}(\mathrm{AI}) / \mathrm{ml} \\
\text { Imidacloprid }\end{array}$} \\
\hline & Acetemiprid & Thiamethoxam & \\
\hline Eretmocerus eremicus & 108.27 & 1.01 & 1.93 \\
\hline Encarsia formosa & 12.02 & 0.397 & 0.980 \\
\hline Gonatocerus ashmeadi & 0.134 & 1.44 & 2.63 \\
\hline Aphytis melinus & 0.005 & 0.105 (24 h exposure time) & 0.246 \\
\hline
\end{tabular}


In another study, Anagyrus pseudococci (a nectar-feeding wasp) was fed using buckwheat (Fagopyrum esculentum) flowers that had been exposed to imidacloprid as a soil treatment, applied at the label rate. Only $38 \%$ of the wasps survived after 1 day, compared to $98 \%$ fed on untreated flowers. This decreased to $0 \%$ survivorship after 7 days for treated flowers, compared to $57 \%$ on the untreated flowers (Krischik et al. 2007).

As stated in the section on exposure routes, exposure to imidacloprid did not affect mortality of G. ashmeadi (a parasitoid wasp) during development within its host, and the adults were sensitive during emergence from the host egg. When mortality was assessed within $48 \mathrm{~h}$ of emergence, the $\mathrm{LC}_{50}$ for the parasitoid was $66 \mathrm{ng}$ of imidacloprid per $\mathrm{cm}^{2}$ leaf (Byrne and Toscano 2007).

Neonicotinoids are commonly used in household products as highly concentrated bait formulations to control ants (Rust et al. 2004; Jeschke et al. 2010); however, the use of agrochemical products at less concentrated doses is an issue for non-target ants. For the leafcutter ant Acromyrmex subterraneus subterraneus, Galvanho et al. (2013) found that sublethal doses of imidacloprid reduced grooming behaviour. Grooming behaviour in this ant is a defence against pathogenic fungi like Beauveria species. Barbieri et al. (2013) recently discovered that interactions between different ant species may be negatively affected using sublethal doses of neonicotinoids. In interspecific interactions, individuals of a native ant species (Monomorium antarcticum) lowered their aggression towards an invasive ant species (Linepithema humile) although survival was not affected. Exposed individuals of L. humile displayed an increase in aggression with the outcome that the probability of survival was reduced.

\section{Hemiptera}

Whilst many Hemiptera are acknowledged as being problematic agricultural pests, a number are important predators of these pests, although they do also feed on some plant tissues, which would be contaminated by neonicotinoids (Prabhaker et al. 2011). Table 4 shows $\mathrm{LC}_{50}$ rates for different Hemiptera species.

\section{Neuroptera}

It is not only the agricultural use of neonicotinoids that affects beneficial invertebrates. In one study, Marathon $1 \% \mathrm{G}$, a product for amateur use on flowers containing imidacloprid, had been found to affect lacewings (Chrysopa spp.) when used at the label rate. Survival rates on untreated flowers were found to be $79 \%$ for adults, compared to $14 \%$ on treated flowers over a 10 day period (Rogers et al. 2007).

\section{Coleoptera}

A number of studies have looked into the effects of neonicotinoids on various taxa of Coleoptera such as Histeridae (Hister beetles) (Kunkel et al. 1999), Carabidae (ground beetles) (Kunkel et al. 2001; Mullin et al. 2010) and Coccinellidae (ladybird beetles) (Smith and Krischick 1999; Youn et al. 2003; Lucas et al. 2004; Papachristos and Milonas 2008; Moser and Obrycki 2009; Eisenback et al. 2010; Khani et al. 2012).

Some Coleoptera, notably in the carabid and staphyliniid families, are voracious predators and are a vital aspect of integrated pest management. For example, although the provision of beetle banks as nesting habitat takes land out of crop production, in wheat (Triticum aestivum) fields, any losses have been found to be more than offset by savings from a reduced need for aphid-controlling pesticides (Landis et al. 2000).

Many of these beetle groups are undergoing rapid declines. In the UK, three quarters of carabid species have reduced in numbers, half of which have been undergoing population declines of more than $30 \%$, although the reason for these considerable declines are unknown (Brooks et al. 2012). These groups have been particularly useful as bioindicators, due to their sensitivity to habitat changes especially in agricultural environments (Kromp 1999; Lee et al. 2001). In the EU Draft Assessment Report for imidacloprid, acute toxicity tests were
Table $4 \mathrm{LC}_{50}$ rates for different Hemiptera species

\begin{tabular}{lllll}
\hline Species & Chemical & \multicolumn{2}{l}{$\mathrm{LC}_{50}$ residual contact (mg AI/l) } & \\
\cline { 3 - 4 } & & Nymphs & Adults & \multirow{2}{*}{ Reference } \\
\hline Orius Laevigatus & Imidacloprid & 0.04 & 0.3 & Delbeke et al. (1997) \\
Hyaliodes vitripennis & Thiacloprid & 1.5 & 0.3 & Bostanian et al. (2005) \\
Hyaliodes vitripennis & Thiamethoxam & 1.43 & 0.5 & Bostanian et al. (2005) \\
Geocoris punctipes & Imidacloprid & & 5,180 & Prabhaker et al. (2011) \\
& Thiamethoxam & & 2,170 & \\
Orius insidiosus & Imidacloprid & & 2,780 & \\
& Thiamethoxam & & 1,670 & \\
\hline
\end{tabular}


undertaken on the carabid beetle Poecilus cupreus, finding the larvae to be highly sensitive. Despite the rapporteur Member State deeming that the concentrations tested were too high for it to conclude no risk to carabids for use on sugar beet, there was no indication of further research required (EFSA 2006).

When exposed to turf plots treated with imidacloprid, the carabid beetle Harpalus pennsylvanicus displayed a range of neurotoxic problems including paralysis, impaired walking and excessive grooming. These abnormal behaviours then rendered the individuals vulnerable to predation from ants (Kunkel et al. 2001). A study by Mullin et al. (2010) exposed 18 different carabid species to corn seedlings treated to fieldrelevant doses of either imidacloprid, thiamethoxam or clothianidin. Nearly $100 \%$ mortality was observed for all species over 4 days.

Coccinellids predators are well known for their ability to control common pests, both in agricultural and domestic environments. In soil treatments of imidacloprid, reduced mobility and delayed reproduction have been found in pollenfeeding species such as Coleomegilla maculata (Smith and Krischick 1999), whilst egg production and oviposition periods of the Mealybug destroyer (Cryptolaemus montrouzieri) (Khani et al. 2012) and Hippodamia undecimnotata (Papachristos and Milonas 2008) were significantly reduced. Table 5 shows available acute toxicity for some coccinellid species.

Harmonia axyridis (harlequin ladybird) larvae were exposed to corn seedlings grown from seeds treated with the label recommended doses of either thiamethoxam or clothianidin. Seventy-two percent of the larvae exhibited neurotoxic symptoms such as trembling, paralysis and loss of coordination, with only $7 \%$ recovery from the poisoning (Moser and Obrycki 2009).

\section{Arachnida}

In addition to crop protection, applications of neonicotinoid insecticides in veterinary medicine have expanded. Imidacloprid is applied to domestic pets as a spot-on formulation against ear mites (Otodectes cynotis) (Jeschke et al. 2010). However, studies on mites have found a positive effect on population numbers. Zeng and Wang (2010) found that sublethal doses of imidacloprid (determined for the green peach aphid (Myzus persicae)) significantly increased the hatch rate of eggs and pre-adult survivorship of the carmine spider mite (Tetranychus cinnabarinus). James and Price (2002) also found that imidacloprid increased egg production by $23-26 \%$ in two-spotted spider mites (Tetranychus urticae) in the laboratory. Another study found that fecundity of this species was slightly elevated when treated with thiamethoxam (Smith et al. 2013).

Szczepaniec et al. (2013) discovered that the application of neonicotinoids supressed expression of plant defence genes when applied to cotton and tomato plants. These genes alter the levels of phytohormones and decrease the plant's resistance to spider mites (T. urticae). When mites were added to the crops, population growth increased from 30 to over $100 \%$ on neonicotinoid-treated plants in the greenhouse and up to $200 \%$ in the field experiment. This study was prompted after the same author had investigated an outbreak of $T$. urticae in New York City, USA. In an attempt to eradicate the emerald ash borer beetle (Agrillus planipennis) from Central Park, imidacloprid was applied to trees as a soil drench and trunk injections. This resulted in an outbreak of T. urticae on elms due to the natural predators being poisoned through ingestion of prey exposed to imidacloprid, combined with fecundity elevation in the mites themselves (Szczepaniec et al. 2011).

Another study found that thiamethoxam and imidacloprid treatments significantly increased two-spotted spider mite (T. urticae) densities on cotton plants when compared to the untreated controls (Smith et al. 2013). This study suggested that the increased usage of neonicotinoids could explain the recent infestation increases of two-spotted spider mite occurring in various crops across the mid-south of the USA.

Table 5 Acute neonicotinoid toxicity for different Coccinellid species

\begin{tabular}{|c|c|c|c|c|}
\hline Species & Chemical & $\mathrm{LD}_{50}$ (ng AI per beetle) & $\mathrm{LC}_{50}(\mu \mathrm{g} \mathrm{AI} / \mathrm{ml})$ & Reference \\
\hline Sasajiscymnus tsugae & Imidacloprid & 0.71 & & Eisenback et al. (2010) \\
\hline Harmonia axyridis & Imidacloprid & & 364 & Youn et al. (2003) \\
\hline Harmonia variegata & Thiamethoxam & & 788.55 & Rahmani et al. (2013) \\
\hline Cryptolaemus montrouzieri & Imidacloprid & & $17.25-23.9$ & Khani et al. (2012) \\
\hline Coccinella undecimpunctata & Imidacloprid & & 34.2 & Ahmad et al. (2011) \\
\hline Coccinella undecimpunctata & Acetamiprid & & 93.5 & Ahmad et al. (2011) \\
\hline Coleomegilla maculata — adult & Imidacloprid & 0.074 & & Lucas et al. (2004) \\
\hline Coleomegilla maculata - larvae & Imidacloprid & 0.034 & & Lucas et al. (2004) \\
\hline
\end{tabular}


Earthworms (Lumbricidae)

Earthworms are vitally important members of the soil fauna, especially in agricultural soils where they can constitute up to $80 \%$ of total soil animal biomass (Luo et al. 1999). They play critical roles in the development and maintenance of soil physical, chemical and biological properties (Lee 1985). Their activities improve soil structure by increasing porosity and aeration, facilitating the formation of aggregates and reducing compaction (Edwards and Bohlen 1996; Mostert et al. 2000). Soil fertility is enhanced by earthworm effects on biogeochemical cycling (Coleman and Ingham 1988; Bartlett et al. 2010), the modification of microbial biomass and activity (Sheehan et al. 2008), breakdown of plant litter (Knollengberg et al. 1985) and the mixing of litter with soil (Wang et al. 2012a).

Neonicotinoid and other systemic insecticides can pose a risk of harm to earthworm survival and behaviour, potentially disrupting soil development and maintenance processes. The same neural pathways that allow neonicotinoids to act against invertebrate pests (Elbert et al. 1991) are also present in earthworms (Volkov et al. 2007). Thus, when neonicotinoids are applied for the protection of agricultural and horticultural crops, earthworms can be exposed by direct contact with the applied granules or seeds, or with contaminated soil or water. Moreover, their feeding activities may result in ingestion of contaminated soil and organic particles (e.g. Wang et al. 2012b). Foliar residues in plant litter after systemic uptake from soils or from direct plant injections also pose a risk to litter-feeding earthworms that consume the contaminated plant litter (e.g. Kreutzweiser et al. 2009).

Neonicotinoids can persist and move in soils thereby increasing the likelihood that earthworms will be exposed for extended periods of time. Laboratory and field trials with neonicotinoids have demonstrated that their half-life in soils varies depending on soil conditions but can range from several weeks to several years (Cox et al. 1997; Sarkar et al. 2001; Cox et al. 2004; Bonmatin et al. 2005; Fossen 2006; Gupta and Gajbhiye 2007; Goulson 2003). Imidacloprid is the most widely used neonicotinoid, and its adsorption to soils is increased by moisture and organic matter content (Broznic et al. 2012), resulting in increased imidacloprid concentrations in organic-rich soils compared to low-organic soils (Knoepp et al. 2012). Earthworms generally prefer moist, organicrich soils. When soil organic carbon content is low, the high solubility of imidacloprid renders it mobile and it is readily moved through soils (Broznic et al. 2012; Knoepp et al. 2012; Kurwadkar et al. 2013), thereby increasing the likelihood that earthworms could be exposed to the pesticide in soils outside the direct area of application.
Effects on survival

Neonicotinoids can be highly toxic to earthworms. However, reported median lethal concentrations $\left(\mathrm{LC}_{50}\right)$ were variable depending on the particular insecticide, test conditions, route of exposure and duration (Table 6). In 13 separate studies, the reported $\mathrm{LC}_{50}$ ranged from 1.5 to $25.5 \mathrm{ppm}$, with a mean of 5.8 and median of $3.7 \mathrm{ppm}$. In seven studies that reported lowest concentrations at which effects on survival were measureable, those lowest effective concentrations ranged from 0.7 to $25 \mathrm{ppm}$, with a mean of 4.7 and median of $1.0 \mathrm{ppm}$. Eisenia fetida was the most common test species in these survival studies and represented the range of reported lethal concentrations, giving little indication from among these studies that other species were more sensitive than $E$. fetida.

When compared to other common insecticides, neonicotinoids tend to be among the most toxic to earthworms. Wang et al. (2012a) tested the acute toxicities of 24 insecticides to E. fetida and found that the neonicotinoids were the most toxic in soil bioassays and that acetamiprid and imidacloprid in particular were the two most toxic insecticides overall. They also reported that a contact toxicity bioassay demonstrated that the neonicotinoids were extremely toxic by a contact route of exposure $\left(\mathrm{LC}_{50}\right.$ of 0.0088 to $0.45 \mu \mathrm{g} \mathrm{cm}^{-2}$ ), although the units of contact toxicity concentration were difficult to compare to standard lethal concentrations. Across a broader range of 45 pesticides, Wang et al. (2012b) found that in soil bioasssays, the neonicotinoid insecticide, clothianidin, was the most toxic pesticide to E. fetida. Alves et al. (2013) compared three insecticides used for seed treatment and reported that imidacloprid was the most toxic to earthworms. In soil bioassays with five different insecticides, Mostert et al. (2002) found that imidacloprid was the second most toxic (behind carbaryl) to earthworms. We found only two studies that reported the toxicity of fipronil, another common, agricultural systemic insecticide, and both found it to be substantially (at least 100 times) less lethal to earthworms than the neonicotinoids (Mostert et al. 2002; Alves et al. 2013).

\section{Effects on reproduction}

Only a few studies tested sublethal effects of neonicotinoids on earthworm reproduction, but it is apparent that reductions in fecundity can occur at low concentrations (Table 6). Baylay et al. (2012) reported $\mathrm{EC}_{50} \mathrm{~s}$ for imidacloprid and thiacloprid against cocoon production by Lumbricus rubellus of 1.5 and 1.3 ppm, respectively, whilst Gomez-Eyles et al. (2009) found similar $\mathrm{EC}_{50}$ s for the same two insecticides at 1.4 and $0.9 \mathrm{ppm}$ for E. fetida. The latter study also reported measurable reductions in cocoon production at $0.3 \mathrm{ppm}$ of thiacloprid. Alves et al. (2013) reported an $\mathrm{EC}_{50}$ for reproduction effects of imidacloprid on Eisenia andrei of $4 \mathrm{ppm}$ with measureable 


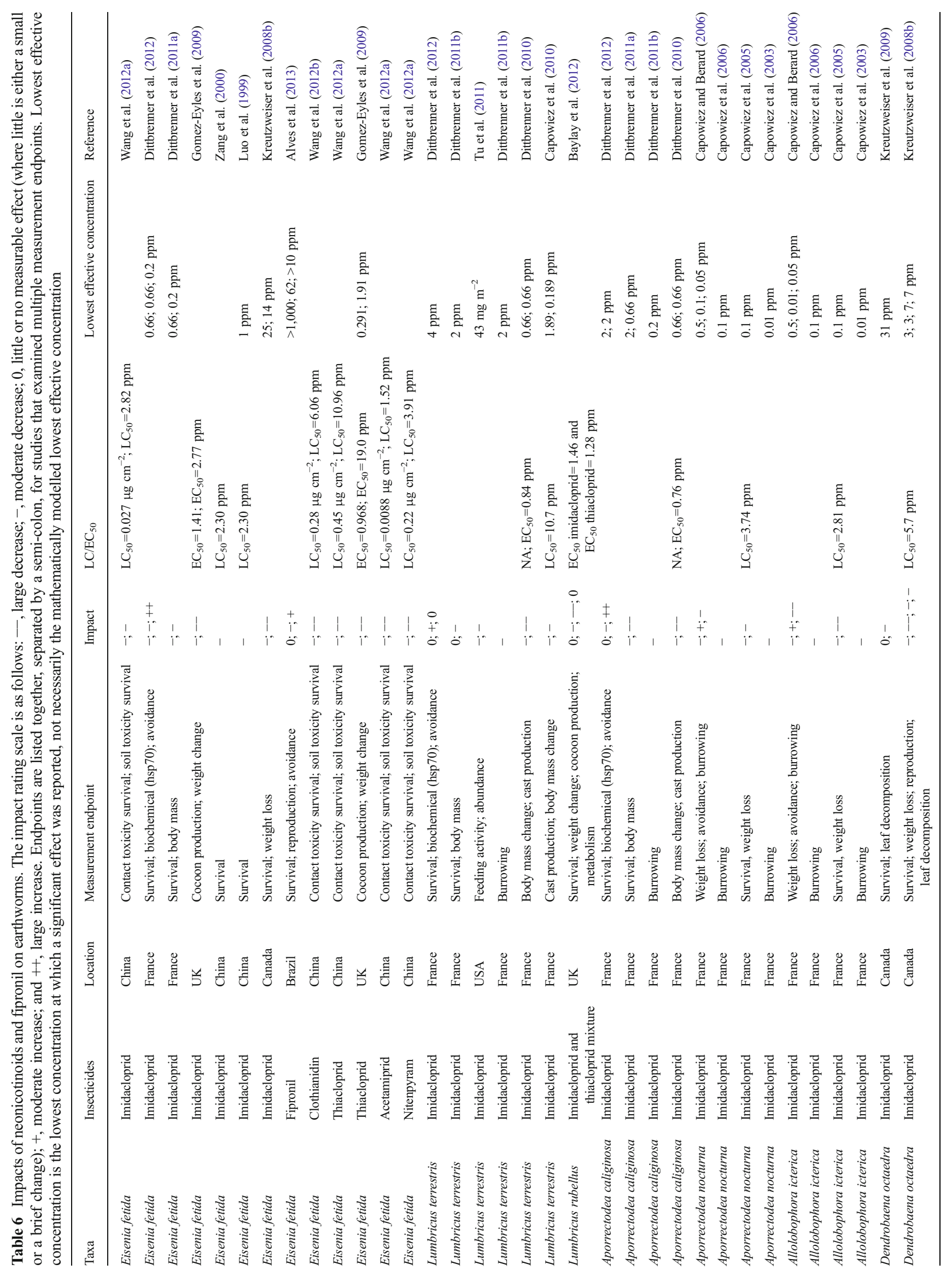




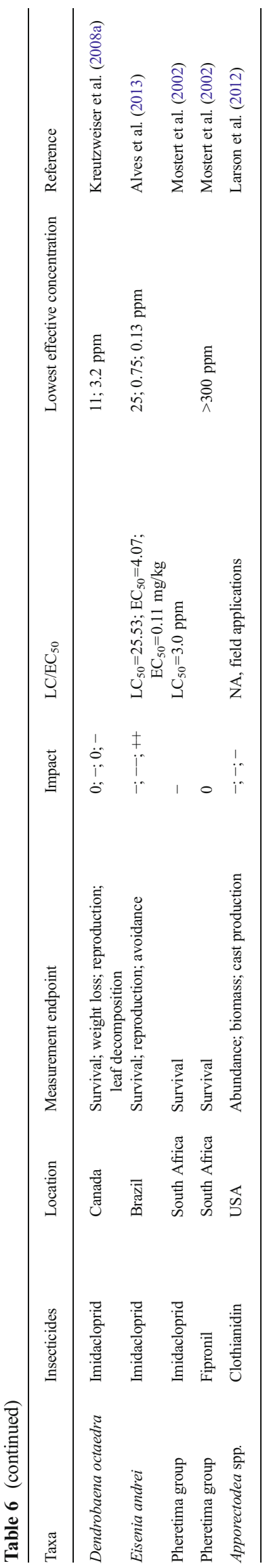

adverse effects at $0.7 \mathrm{ppm}$. Kreutzweiser et al. (2008b) tested the effects of imidacloprid in forest litter on the litter-dwelling earthworm Dendrobaena octaedra and reported significant reductions in cocoon production among surviving earthworms at $7 \mathrm{ppm}$.

\section{Effects on behaviour}

A number of studies focused on behavioural endpoints under the premise that effects on behaviour are often ultimately linked to population or community effects (Little 1990; Dittbrenner et al. 2012). The behavioural attributes considered here are avoidance behaviour, burrowing, cast production and weight change (as an indicator of feeding behaviour). Among the 31 reported values for behavioural effects, weight change was the most common, followed by burrowing, avoidance behaviour and cast production (Table 6). Only a few studies gave median effective concentrations $\left(\mathrm{EC}_{50}\right)$, and they ranged from 0.1 (avoidance) to 19 (weight change) ppm, with a mean $\mathrm{EC}_{50}$ of 3.7 and median of $1.3 \mathrm{ppm}$. These behavioural $\mathrm{EC}_{50} \mathrm{~S}$ were about 1.5 to 2.8 times lower than the mean and median lethal concentrations of 5.8 and $3.7 \mathrm{ppm}$.

However, many more studies reported lowest concentrations at which behavioural effects were detected, and those ranged from 0.01 to $14 \mathrm{ppm}$ with a mean of 1.2 and median of $0.5 \mathrm{ppm}$. Thus, measurable behavioural effects were more sensitive endpoints than measurable survival effects. Measurable behavioural effects occurred at concentrations of about two to four times lower than the mean and median lowest effective concentrations on survival of 4.7 and $1.0 \mathrm{ppm}$. Burrowing (smaller, shorter, more narrow burrows) was the most sensitive behavioural endpoint with effects detected at mean and median concentrations of 0.3 and $0.07 \mathrm{ppm}$ (range 0.01 to $2, n=8$ ). Avoidance behaviour was the next most sensitive endpoint with effects detected at mean and median concentrations of 0.5 and $0.13 \mathrm{ppm}(n=5)$, followed by cast production (mean 1.1, median $0.7 \mathrm{ppm}, n=3$ ) and weight change (mean 2.1, median $0.7 \mathrm{ppm}, n=13$ ). All of these indicate that measurable adverse effects on earthworm behaviour would be expected at neonicotinoid concentrations below $1 \mathrm{ppm}$ in soil.

\section{Risks to earthworms}

The actual risk of harmful effects on earthworm populations posed by neonicotinoid insecticides will depend on exposure concentration, exposure duration, route of exposure, rate of uptake and inherent species sensitivity. From the toxicity studies reviewed here, it appears that individual earthworms across all common species are at risk of mortality if they consume soil or organic particles with neonicotinoid insecticide concentrations of about $1 \mathrm{ppm}$ or higher for several days. Higher numbers (up to $50 \%$ ) of earthworms would be 
expected to be at risk of mortality when concentrations reach about 3 ppm and higher. Although it was difficult to compare the exposure concentrations to standard bioassays, it appears that the risk of mortality from surface contact exposure can be ten times or more higher than the risk of mortality from consumption of contaminated soils (Wang et al. 2012a). On the other hand, the route of exposure can affect the likelihood of lethal effects on earthworms. When earthworms were exposed to foliar residues in leaf litter from imidaclopridinjected trees, a significant feeding inhibition effect was detected that reduced leaf consumption but did not cause earthworm mortality, even at concentrations of about $10 \mathrm{ppm}$ (Kreutzweiser et al. 2008a).

The risk of sublethal effects on some important behavioural attributes is higher than the risk of mortality to individuals. Insecticide effects on burrowing and avoidance behaviours would be expected at concentrations of about 0.1 to $0.5 \mathrm{ppm}$ and higher. Whilst alterations in burrowing behaviour, especially reductions in burrowing depths, have implications for the transfer properties of soils (Capowiez et al. 2006; Dittbrenner et al. 2011b), the consequences in real-world field conditions are not clear. Fewer, smaller and shorter burrows could reduce air, water and solute transport through soils affecting overall soil ecology, but none of the studies we found actually tested these implications in experimental or field settings.

The concentrations that pose risk of mortality (assuming high toxicity by contact exposure) and sublethal effects on earthworms fall within the range of reported field concentrations, albeit at the upper end of that range of concentrations. Dittbrenner et al. (2011b) indicate that predicted environmental concentrations for imidacloprid in agricultural soils would be about 0.3 to $0.7 \mathrm{ppm}$, suggesting risks of at least sublethal effects on earthworms could be quite high. Bonmatin et al. (2005) reported that imidacloprid in soils can reach several hundred parts per billion shortly after sowing of treated seeds. Soil samples from a tea plantation treated with clothianidin had average concentrations of up to $0.45 \mathrm{ppm}$ shortly after application (Chowdhury et al. 2012). Donnarumma et al. (2011) found concentrations of imidacloprid in soils at about 0.6 to 0.8 ppm by 2 weeks after application of treated seeds. Ramasubramanian (2013) reported clothianidin concentrations in soils of 0.27 to 0.44 ppm up to 3 days after single applications and 0.51 to $0.88 \mathrm{ppm}$ by 3 days after double applications of water-soluble granules. Collectively, these studies show that operational applications of neonicotinoids can result in soil concentrations that are likely to pose a high risk of sublethal effects and potential risk of lethal effects (especially by contact toxicity) to earthworms.

At least two issues related to the assessment of risk to earthworms from exposure to neonicotinoids have not been adequately addressed in the published literature. The first is the length of exposure periods in toxicity testing compared to the length of exposure to persistent concentrations in natural soils. Most toxicity tests are short term, in the order of days to weeks. On the other hand, neonicotinoid residues can persist in soils for months to years (Bonmatin et al. 2014, this issue). For most pesticides, lethal or effective concentrations become lower as exposure periods increase, and this is likely the case for neonicotinoids (Tennekes 2010; Tennekes and SánchezBayo 2012, 2013; Rondeau et al. 2014). It is plausible that long-term low-level concentrations of neonicotinoids in soils may pose higher risk to earthworms than what can be inferred from the published toxicity tests. The second issue pertains to the heterogeneous distribution of neonicotinoid residues in natural soils. When residues enter the soil at the surface from spray or granule deposition or from litter fall, concentrations in soils are likely to be higher on or near the surface than in deeper soils. Residues entering soils from planted seed or from contaminated water are likely to be higher at or near the source of contamination than elsewhere. Both situations would result in concentration "hot spots" near the points of entry. Conversely, most toxicity tests prepare test concentrations as parts per million (or equivalent) and assume complete mixing. Therefore, levels of exposure to earthworms at or near those hot spots in natural soils will consequently be higher than would be predicted from residue analyses of bulk samples from laboratory or field test systems.

Mortality or behavioural effects on individual earthworms do not necessarily translate to population effects with ecological consequences. Populations of organisms with short generation times (e.g. several generations per year as is the case for most earthworm species) and/or high dispersal capacity have a higher likelihood of recovery from pesticide-induced population declines than those with longer regeneration periods and limited dispersal capacity (Kreutzweiser and Sibley 2013). However, the tendency for neonicotinoids to persist in organic soils reduces the likelihood of this recovery pathway because subsequent generations may be exposed to concentrations similar to those to which the parent generation was exposed. Life history strategies and their influences on community responses and recovery from pesticide effects have been demonstrated by population modelling of other nontarget organisms (Wang and Grimm 2010), and similar principles may apply to assessing risks to overall earthworm populations and communities. Population models that account for differential demographics and population growth rates within communities have been shown to provide more accurate assessments of potential pesticide impacts on populations and communities than conventional lethal concentration estimates can provide (Stark and Banks 2003). The use of ecological models to incorporate a suite of factors including seasonal variations, community assemblage mechanisms and lethal and sublethal insecticide effects and their influences on the risks to organisms, populations or communities can provide useful insights into receptor/pesticide interactions and 
can thereby improve risk assessments (Bartlett et al. 2010). Ecological and population modelling combined with pesticide exposure modelling and case-based reasoning (drawing on past experience or information from similar chemical exposures) can provide further refinements and improve risk assessment for earthworm communities and their ecological function (van den Brink et al. 2002). Empirical field studies of earthworm population responses to realistic field concentrations of neonicotinoids are lacking and would greatly improve risk assessment efforts.

\section{Aquatic invertebrates}

Freshwater invertebrates

Aquatic invertebrates are extremely important components of aquatic ecosystems. They play roles as decomposers, grazers, sediment feeders, parasites and predators. They also provide much of the food that vertebrates associated with these systems feed upon. Pesticides, including neonicotinoids, reach surface waters through various routes, but in particular through atmospheric deposition (drift) after application by various sprayers, by surface runoff and by seepage of contaminated groundwater. Aquatic invertebrates are particularly susceptible to pesticides. Unlike terrestrial organisms, aquatic organisms generally cannot avoid exposure easily by moving to uncontaminated areas, particularly when pesticides are water soluble. Uptake of pesticides in aquatic invertebrates occurs through respiration (gills and trachea), feeding and through the epidermis, be it cuticle or skin.

Neonicotinoids have been used for a comparatively shorter period of time than other insecticides. However, they are found in freshwater systems more and more frequently. For example, surface water monitoring for pesticides in California has revealed that imidacloprid has frequently exceeded water quality guidelines of $1 \mathrm{ppb}$ (Starner and Goh 2012). In the Washington State, USA, the State Department of Ecology and the State Department of Agriculture have been monitoring salmon-bearing rivers and streams for pesticides, including imidacloprid for a number of years and this insecticide is frequently found (http://agr.wa.gov/PestFert/natresources/ $\mathrm{SWM} /$ ).

However, even though imidacloprid and other neonicotinoids are present in freshwater systems, the question remains to what extent such concentrations affect aquatic organisms in the field. Here we discuss a number of studies dealing with neonicotinoid toxicity to aquatic invertebrates and make some observations about their potential impact on aquatic ecosystems.

\section{Laboratory studies}

Crustacea and Amphipoda Several laboratory studies have been published on the toxicity of the neonicotinoid imidacloprid on a range of aquatic invertebrates (Table 7). Stark and Banks (2003) developed acute toxicity data and population-level toxicity data for the water flea Daphnia pulex exposed to thiamethoxam (Actara). Thiamethoxam was the least toxic insecticide evaluated in this study of seven insecticides, and its $\mathrm{LC}_{50}$ of $41 \mathrm{ppm}$ was well above any anticipated concentration expected to be found in surface water systems.

Chen et al. (2010) estimated the acute toxicity of imidacloprid to the water flea, Ceriodaphnia dubia $\left(\mathrm{LC}_{50}=\right.$ $2.1 \mathrm{ppb}$ ), and the chronic toxicity to C. dubia populations. The effects of the adjuvant, R-11 alone and in combination with imidacloprid were also assessed. In the population study, exposure of $C$. dubia to imidacloprid concentrations of $0.3 \mathrm{ppb}$ reduced population size to $19 \%$ of the control population. This concentration is well below the U.S. EPA's expected environmental concentration of $17.4 \mathrm{ppb}$, indicating that imidacloprid may cause damage to aquatic invertebrates in the field.

The acute and chronic effects of imidacloprid on the amphipod Gammarus pulex were studied by Nyman et al. (2013). Feeding by G. pulex and body lipid content were significantly reduced after exposure to a constant imidacloprid concentration of $15 \mathrm{ppb}$. Furthermore, G. pulex individuals were unable to move and feed after 14 days of constant exposure resulting in a high level of mortality.

Interestingly, the standard test organism Daphnia magna is especially insensitive to neonicotinoids (Beketov and Liess 2008). An acute $\mathrm{LC}_{50}$ of around $7,000 \mathrm{ppb}$ is several orders of magnitude above effective concentrations found for several other invertebrates. This implies that D. magna cannot be used as a sensitive test organism protective for many species.

Insecta Acute toxicity estimates of neonicotinoids on aquatic insects have also been published. $\mathrm{LC}_{50}$ estimates for aquatic insects range from 3 to $13 \mathrm{ppb}$. Imidacloprid $\mathrm{LC}_{50}$ estimates for the mayfly Baetis rhodani, the black fly Simulium latigonium (Beketov and Liess 2008) and the mosquito Aedes taeniorhynchus (Song et al. 1997) are $8.5,3.7$ and $13 \mathrm{ppb}$, respectively. $\mathrm{LC}_{50}$ estimates for $B$. rhodani and $S$. latigonium exposed to thiacloprid were 4.6 and $3.7 \mathrm{ppb}$, respectively (Beketov and Liess 2008). A chronic $\mathrm{LC}_{50}$ of $0.91 \mathrm{ppb}$ was reported for the midge Chironomus tentans for imidacloprid (Stoughton et al. 2008). A study on the effects of imidacloprid as a mixture with the organophosphate insecticides dimethoate and chlorpyrifos on the midge Chironomus dilutus found that imidacloprid acted synergistically with chlorpyrifos and antagonistically with dimethoate (LeBlanc et al. 2012). 


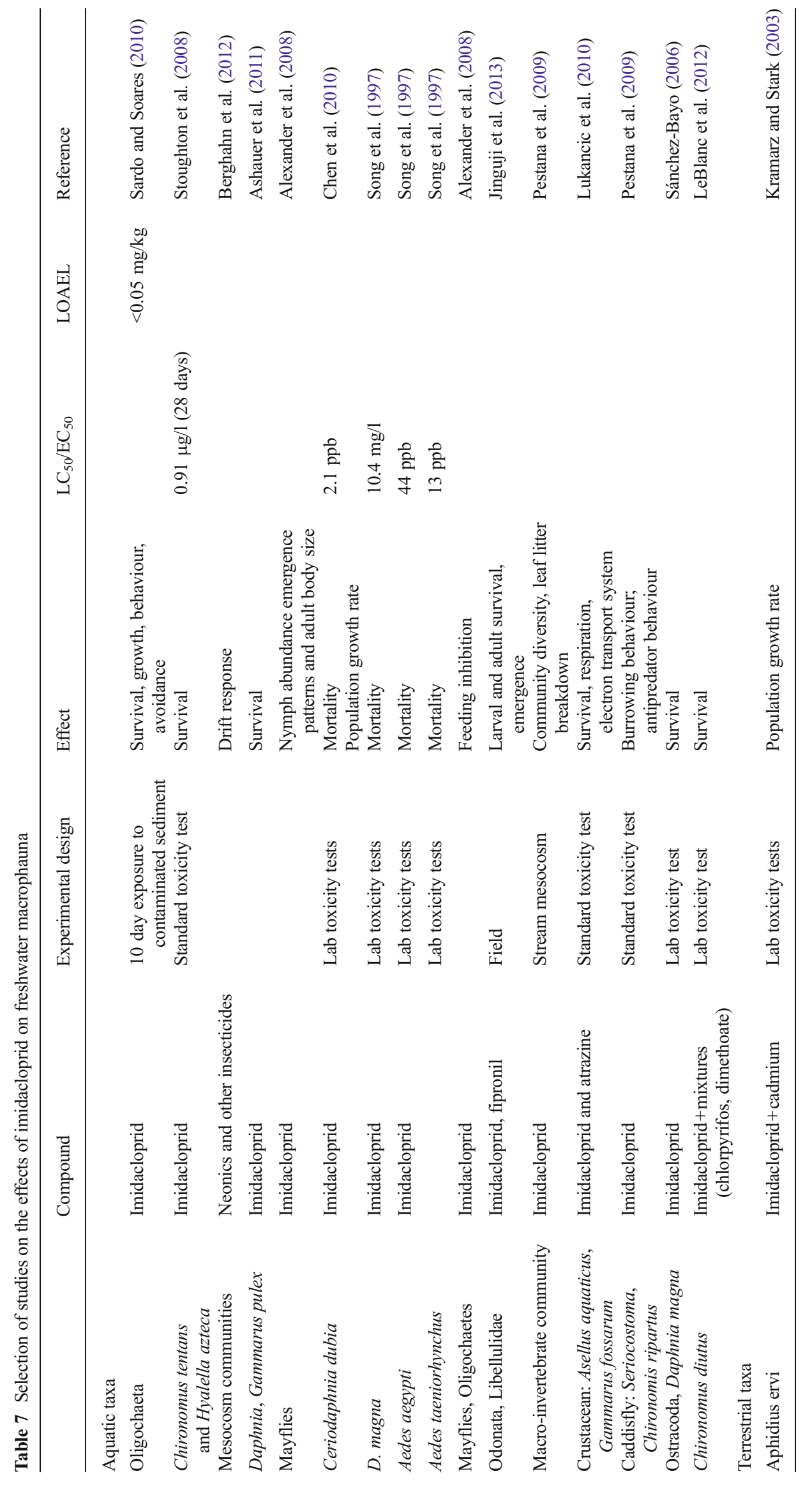


Oligochaetes Sardo and Soares (2010) investigated the effects of imidacloprid on the aquatic oligochaete Lumbriculus variegatus. They exposed this worm species to imidacloprid concentrations ranging from 0.05 to $5.0 \mathrm{mg} / \mathrm{kg}$ sediment. Mortality was fairly low (35\% in the highest concentration), but $L$. variegatus avoided imidacloprid-contaminated sediment. Furthermore, individual growth (biomass) was inhibited at all concentrations tested compared to the control.

Mesocosm studies Alexander et al. (2008) examined the effect of imidacloprid as a 12 day pulse or 20 day continuous exposure on the mayflies Epeorus spp. and Baetis spp. Nymph densities were reduced after both types of exposures. Sublethal effects were observed as well. Adults were smaller and had smaller head and thorax size after exposure to imidacloprid concentrations as low as $0.1 \mathrm{ppb}$. However, these effects were only found in males.

Within community test systems, neonicotinoids had strong effects especially on insects (Hayasaka et al. 2012). However, to our knowledge, all experiments investigating a dose-response relationship observed effects at the lowest concentrations evaluated. Hence, it is difficult to establish a NOEC. Within outdoor mesocosm studies, a LOEC of $1.63 \mathrm{ppb}$ was estimated for imidacloprid. Adverse effects on benthic communities with $5 \%$ reductions in the abundance of invertebrates were observed by Pestana et al. (2009). For thiacloprid, strong effects on sensitive long living insects were observed at pulsed exposure to $0.1 \mathrm{ppb}$ (Liess and Beketov 2011), the lowest effective concentration observed so far in communities.

Berghahn et al. (2012) conducted stream mesocosm studies whereby $12 \mathrm{~h}$ pulses of imidacloprid (12 ppb) were introduced three times at weekly intervals. Results showed that drift of insects and the amphipod Gammarus roeseli increased after exposure to pulses of imidacloprid. These results indicated that imidacloprid was having a negative effect on $G$. roeseli.

In another stream mesocosm study, Böttger et al. (2013) evaluated pulses of imidacloprid on G. roeseli. The number of brood carrying females was reduced in the imidacloprid treatments compared to the control groups in the last 3 weeks of the study.

The populations of an aquatic invertebrate, the common mosquito Culex pipiens, exposed over several generations to repeated pulses of low concentrations of the neonicotinoid thiacloprid, continuously declined and did not recover in the presence of a less sensitive competing species, the water flea $D$. magna. By contrast, in the absence of a competitor, insecticide effects on the more sensitive species were only observed at concentrations one order of magnitude higher, and the species recovered more rapidly after a contamination event. The authors conclude that repeated toxicant pulse of populations that are challenged with interspecific competition may result in a multigenerational culmination of low-dose effects (Liess et al. 2013).

Risk to aquatic ecosystems A species sensitivity distribution (SSD) of acute toxicity data for a wider range of species, including ostracods, cladocerans and other aquatic organisms, predicts a hazardous concentration for $5 \%$ of aquatic species (HC5) for imidacloprid in water in the range 1.04-2.54 ppb (Sanchez-Bayo and Kouchi 2012).

Van Dijk et al. (2013) developed a regression analysis for abundance of aquatic macro-invertebrate species and nearby imidacloprid concentrations in Dutch surface waters. Data from 8 years of nationwide monitoring covering 7,380 different locations of macro-invertebrate samples and 801 different locations of imidacloprid samples were pooled. Next, the biological samples (macro-invertebrate abundance counts) were combined with nearby (in space and time) chemical samples (imidacloprid concentrations), and next, a statistical analysis was done on the complete pooled combined dataset. They found that macro-invertebrate abundance consistently declines along the gradient of increasing median nearby imidacloprid concentration in the pooled dataset. This pattern turned out to be robust: it is independent of year and location. Overall, a significant negative relationship $(P<0.001)$ was found between abundance of all macro-invertebrate species pooled and nearby imidacloprid concentration. A significant negative relationship was also found for abundance of each of the pooled orders Amphipoda, Basommatophora, Diptera, Ephemeroptera and Isopoda, and for several species separately. The order Odonata had a negative relationship very close to the significance threshold of $0.05(P=0.051)$. In accordance with previous research, a positive relationship between abundance and nearby imidacloprid pollution was found for the order Actinedida. However, other pesticides were not included into the analyses by Van Dijk et al. (2013). Therefore, possible co-linearity or synergisms between neonicotinoids and other pollutants still need to be further explored (Vijver and Van den Brink 2014).

Pesticide exposure was identified to strongly reduce the amount and abundance of vulnerable invertebrate species in streams using the SPEAR approach (Liess and von der Ohe 2005). The approach was extended from German streams to Australian, Danish, French and Finnish streams revealing the same effects of pesticide exposure on vulnerable invertebrate species (Rasmussen et al. 2013; Liess et al. 2008; Schäfer et al. 2012). Beketov et al. (2013) analysed the effect of pesticide presence on invertebrate species richness in European (Germany and France) and Australian streams. They found an overall reduction of $42 \%$ for Europe and $27 \%$ for Australia in species richness between uncontaminated and heavily contaminated streams. The limitation of these studies in the context of assessment of neonicotinoid impact is that toxicity was mainly due to insecticides, other than neonicotinoids, as general usage of the latter only increased recently. 
The results of laboratory and semi-field (mesocosm) studies indicate that aquatic invertebrates are very sensitive to the neonicotinoid insecticides. However, most of the studies we found in the literature were conducted with imidacloprid. For pesticide risk assessment, the published results to date indicate that it may be difficult to predict community-level effects using the tiered aquatic effect assessment scheme and acute and chronic toxicity data. When extrapolating from acute and chronic single species test systems, the assessment factors identified by the uniform principle of the relevant EU legislation (1107/2009) do not predict safe concentrations in multispecies outdoor mesocosms. For example, acute laboratory effects of thiacloprid on sensitive insect species show that effects occur after exposure to the range of 3-13 ppb. Accordingly, an assessment factor of 100 would indicate a safe concentration of 0.03 to $0.13 \mathrm{ppb}$ for thiacloprid. However, outdoor mesocosm results employing a pulsed exposure show a LOEC below $0.1 \mathrm{ppb}$ for thiacloprid (Liess and Beketov 2011). Lower concentrations were not investigated. Obviously, an assessment factor higher than 100 is needed to identify safe concentrations on the basis of acute test results. For the HC5 calculated on acute lethal concentrations, an assessment factor of larger than 10 is necessary (Liess and Beketov 2012). Additionally, in a laboratory study, chronic effects of sensitive insect species were exhibited after exposure to $0.91 \mathrm{ppb}$ imidacloprid. Employing an assessment factor of 10 would indicate a safe concentration of approximately $0.1 \mathrm{ppb}$ imidacloprid. However, this concentration is not safe according to the results obtained in complex community investigations. Unfortunately, to the best of our knowledge, no community-level investigation with imidacloprid evaluating a range of concentrations below $0.1 \mathrm{ppb}$ has been published. This type of study would help with determining a NOEC for imidacloprid. Overall, the results of the published literature indicate that certain neonicotinoids have the potential to cause significant damage to aquatic ecosystems by causing negative effects in individuals and populations of aquatic invertebrates at very low concentrations. Protective concentrations for these products in aquatic systems still need to be determined.

Marine and coastal invertebrates

There is very limited information regarding the assessment of the environmental toxicology and contamination of neonicotinoids in marine ecosystems. Standardised environmental toxicological characterization focuses on only a few species models and rarely examines species that represent keystone organisms in marine or coastal ecosystems (CCME 2007). Monitoring and surveillance of neonicotinoid pollution in marine coastal habitats are non-existent.

Toxicology The earliest published marine ecotoxicological studies of neonicotinoids were with opossum shrimps
(Mysidopsis bahia) which are distributed in marine coastal waters (Ward 1990, 1991; Lintott 1992). Median LC $_{50}$ (96 h) for the technical grade of imidacloprid was $34.1 \mathrm{ppb}$ with a mortality-NOEC of $13.3 \mathrm{ppb}$ (Ward 1990). Exposure to a commercial formulation (ADMIRE) of imidacloprid resulted in a $96 \mathrm{~h}$ mortality-NOEC of $21 \mathrm{ppb}$. Maximum acceptable toxicant concentrations for M. bahia to imidacloprid were 23 parts per trillion (ppt) for growth effects and $643 \mathrm{ppt}$ for reproductive effects (Ward 1991).

Toxicology for other marine arthropods includes Artemia spp. and a brackish water mosquito (Aedes taeniohynchus). The $48 \mathrm{~h} \mathrm{LC}_{50}$ for Artemia was $361 \mathrm{ppm}$, whilst Aedes exhibited a $72 \mathrm{~h} \mathrm{LC}_{50}$ of $21 \mathrm{ppb}$, and a $48 \mathrm{~h} \mathrm{LC}_{50}$ of $13 \mathrm{ppb}$ for an early instar stage of development (Song et al. 1997; Song and Brown 1998). Osterberg et al. (2012) demonstrated that in the blue crab (Callinectes sapidus), megalopae were an order of magnitude more sensitive than juveniles to lethal effects of imidacloprid ( $24 \mathrm{~h}-\mathrm{LC}_{50}=10 \mathrm{ppb}$ for megalopae vs $24 \mathrm{~h}-\mathrm{LC}_{50}=1,1 \mathrm{ppb}$ for juveniles).

There are no known published OECD/EPA parameterbased studies on non-arthropod marine invertebrates. For the marine mussel, Mytilus galloprovincialis, a transcriptomic and proteomic survey was conducted as a response to imidacloprid and thiacloprid exposures (Dondero et al. 2010). This study concluded that the two neonicotinoids induced distinct toxicodynamic responses and that caution should be heeded when conducting ecological risk assessments for chemical mixtures that target the same receptor. Rodrick (2008) demonstrated that imidacloprid had an effect on oyster hemocyte immunocompetence and that there was an additive effect when oysters were exposed to a compound stress of salinity and exposure to imidacloprid. Tomizawa et al. (2008) used the gastropod Aplysia californica as a model to characterize imidacloprid and thiacloprid as agonists of the acetylcholinebinding protein, indicating that neonicotinoids could also affect marine gastropods.

Environmental pollution There are no published works regarding the marine environmental contamination of neonicotinoids. Until recently, there has been little public concern of neonicotinoid non-point source pollution of marine environments from land runoff. At least within the USA, this attitude is beginning to change. In the State of Washington 2013, the Willapa-Grays Harbor Oyster Growers Association received a conditional registration from the U.S. Environmental Protection Agency to use imidacloprid to control native burrowing shrimp in Willapa Bay, Washington that may threaten commercial shellfish beds (EPA Reg. no. 88867-1). In Hawaii, there have been public protests and scrutiny over the use of neonicotinoid pesticides in their industrial agricultural practices and their likely negative impacts on coral reefs and sea grass beds (Sergio 2013). For both Hawaii and the U.S. Virgin Islands, there is concern that the use of 
neonicotinoids as a method for termite control may be polluting and impacting coastal resources.

\section{Conclusion}

At field-realistic levels of pollution, neonicotinoids and fipronil generally have negative effects on physiology and survival for a wide range of non-target invertebrates in terrestrial, aquatic, marine and benthic habitats. Effects are most often found by in vitro testing, using a limited number of test species. This basically means that there is a deficit of information for the grand majority of other invertebrates. In vitro testing to establish safe environmental concentration thresholds is hindered by the fact that most test protocols are based on older methodology, validated for pesticides with very different chemical and toxicological characteristics. New and improved methodologies are needed to specifically address the unique toxicology of these neurotoxic chemicals, including their non-lethal effects and synergistic effects for a variety of terrestrial, aquatic and marine organisms.

The amount of published in vivo field tests is small and experimental setups often suffer from inability to control for variation in (semi)natural circumstances or have insufficient statistical power due to the high financial costs of large robust field experiments. Given the clear body of evidence presented in this paper showing that existing levels of pollution with neonicotinoids and fipronil resulting from presently authorized uses frequently exceed lowest observed adverse effect concentrations and are thus likely to have large-scale and wide ranging negative biological and ecological impacts, the authors strongly suggest that regulatory agencies apply more precautionary principles and tighten regulations on neonicotinoids and fipronil.

\footnotetext{
Acknowledgments This manuscript benefited from the discussions in the International Task Force on Systemic Pesticides during its plenary meetings in Paris (2010), Bath (2011), Cambridge (2012), Padua (2012), Louvain-la-Neuve (2013) and Legnaro (2013). The authors are organised in alphabetic order, except the first who is also the corresponding author. All authors work for public agencies, except V. Amaral-Rogers who is employed by Buglife, a UK charity devoted to the conservation of invertebrates, and D.A. Noome, whose independent work for the TFSP is financed by the Stichting Triodos Foundation, and N. Simon-Delso working for CARI (association supported by the Belgium government). Contributions of J. Settele and M. Wiemers were part of www.legatoproject.net (funded by the BMBF, German Ministry for Education and Research). The work has been funded by the Triodos Foundation's Support Fund for Independent Research on Bee Decline and Systemic Pesticides. This Support Fund has been created from donations by Adessium Foundation (The Netherlands), Act Beyond Trust (Japan), Utrecht University (Netherlands), Stichting Triodos Foundation (The Netherlands), Gesellschaft fuer Schmetterlingsschutz (Germany), M.A. O.C. Gravin van Bylandt Stichting (The Netherlands), Zukunft Stiftung Landwirtschaft (Germany), Study Association Storm (Student Association Environmental Sciences Utrecht University) and citizens. The funders had no role in study design, data collection and analysis, decision to publish, or preparation of the manuscript.
}

Conflict of interest The authors declare no conflict of interest.

\section{References}

Abbas N, Shad SA, Razaq M (2012) Fitness cost, cross resistance and realized heritability of resistance to imidacloprid in Spodoptera litura (Lepidoptera: Noctuidae). Pestic Biochem Physiol 103:181188

Abbott VA, Nadeau JL, Higo HA, Winston ML (2008) Lethal and sublethal effects of imidacloprid on Osmia lignaria and clothianidin on Megachile rotundata (Hymenoptera: Megachilidae). J Econ Entomol 101:784-796

Aebischer NJ (1990) Assessing pesticide effects on non-target invertebrates using long-term monitoring and time-series modelling. Funct Ecol 4:369-373

Ahmad M, Sayyed AH, Saleem MA, Ahmad M (2008) Evidence for field evolved resistance to newer insecticides in Spodoptera litura (Lepidoptera: Noctuidae) from Pakistan. Crop Prot 27:1367-1372

Ahmad M, Rafiq M, Arif MI, Sayyed AH (2011) Toxicity of some commonly used insecticides against Coccinella undecimpunctata (Coleoptera: Coccinellidae). Pak J Zool 43:1161-1165

Ahmad S, Ansari MS, Ahmad N (2013) Acute toxicity and sublethal effects of the neonicotinoid imidacloprid on the fitness of Helicoverpa armigera (Lepidoptera: Noctuidae). Int J Trop Insect Sci 33:264-275

Aizen, Harder (2009) The global stock of domesticated honey bees is growing slower than agricultural demand for pollination. Curr Biol 19:915-918

Alaux C, Brunet JL, Dussaubat C, Mondet F, Tchamitchan S, Cousin M, Brillard J, Baldy A, Belzunces LP, Le Conte Y (2010) Interactions between Nosema microspores and a neonicotinoid weaken honeybees (Apis mellifera). Environ Microbiol 12:774-782

Albajes R, López C, Pons X (2003) Predatory fauna in cornfields and response to imidacloprid seed treatment. J Econ Entomol 96:18051813

Alexander AC, Heard K, Culp JM (2008) Emergent body size of mayfly survivors. Freshw Biol 53:171-180

Aliouane Y, El Hassani AK, Gary V, Armengaud C, Lambin M, Gauthier M (2009) Subchronic exposure of honeybees to sublethal doses of pesticides: effects on behavior. Environ Toxicol Chem 28:113-122

Alves PRL, Cardoso EJBN, Martines AM, Sousa JP, Pasini A (2013) Earthworm ecotoxicological assessments of pesticides used to treat seeds under tropical conditions. Chemosphere 90:2674-2682

Anon (2012) EFSA Statement on the findings in recent studies investigating sub-lethal effects in bees of some neonicotinoids in consideration of the uses currently authorised in Europe. EFSA Journal 10: 2752

Ansari MS, Ali H, Shafqat S (2012) Insecticidal effect on a population of Spilarctia obliqua (Lepidoptera: Arctiidae). Entomol Res 42:330 338

Apenet, (2010) http://www.reterurale.it/flex/cm/pages/ServeBLOB.php/ L/IT/IDPagina/3280

Arain MS, Hu XX, Li GQ (2014) Assessment of toxicity and potential risk of butene-fipronil using Drosophila melanogaster, in comparison to nine conventional insecticides. Bull Environ Contam Toxicol 92:190-195

Arena, M., and Sgolastra, F (2014) A meta-analysis comparing the sensitivity of bees to pesticides. Ecotoxicol, 1-11

Asaro C, Creighton J (2011) Use of systemic fipronil and imidacloprid to control regeneration pests of loblolly pine. J Econ Entomol 104: $1272-1279$

Ashauer R, Hintermeister A, Potthoff E, Esche BI (2011) Acute toxicity of organic chemicals to Gammarus pulex correlates with sensitivity 
of Daphnia magna across most modes of action. Aquat Toxicol 103: $38-45$

Aufauvre J, Biron DG, Vidau C, Fontbonne R, Roudel M, Diogon M, Vigues B, Belzunces LP, Delbac F, Blot N (2012) Parasiteinsecticide interactions: a case study of Nosema ceranae and fipronil synergy on honeybee. Scientific reports 2, srep00326srep00326

Balderrama N, Nunez J, Giurfa M, Torrealba J, Dealbornoz EG, Almeida LO (1996) A deterrent response in honeybee (Apis mellifera) foragers: dependence on disturbance and season. J Insect Physiol 42: 463-470

Barbara G, Grünewald B, Paute S, Gauthier M, Raymond-Delpech V (2008) Study of nicotinic acetylcholine receptors on cultured antennal lobe neurones from adult honeybee brains. Invert Neurosci 8:19-29

Barbieri RF, Lester PJ, Miller AS, Ryan KG (2013) A neurotoxic pesticide changes the outcome of aggressive interactions between native and invasive ants. Proc R Soc B Biol Sci 28:20132157

Bartlett MD, Briones MJI, Neilson R, Schmidt O, Spurgeon D, Creamer RE (2010) A critical review of current methods in earthworm ecology: from individuals to populations. Eur J Soil Biol 46:67-73

Baylay AJ, Spurgeon DJ, Svendsen C, Griffin JL, Swain SC, Sturzenbaum SR, Jones OAH (2012) A metabolomics based test of independent action and concentration addition using the earthworm Lumbricus rubellus. Ecotoxicology 21:1436-1447

Beketov MA, Liess M (2008) Potential of 11 pesticides to initiate downstream drift of stream macroinvertebrates. Arch Environ Contam Toxicol 55:247-253

Beketov MA, Kefford BJ, Schäfer RB, Liess M (2013) Pesticides reduce regional biodiversity of stream invertebrates. Proc Natl Acad Sci U S A 110:11039-11043. doi:10.1073/pnas.1305618110

Belzunces LP (2006) Rapport d'étude du programme Etude comparée des impacts de trois classes d'insecticides néonicotinoïdes chez l'abeille. Programme communautaire sur l'apiculture Année 2006

Belzunces LP, Tchamitchian S, Brunet JL (2012) Neural effects of insecticides in the honey bee. Apidologie 43:348-370

Benzidane Y, Touinsi S, Motte E, Jadas-Hécart A, Communal PY, Leduc L, Thany SH (2010) Effect of thiamethoxam on cockroach locomotor activity is associated with its metabolite clothianidin. Pest Manag Sci 66:1351-1359

Berghahn R, Mohr S, Hübner V, Schmiediche R, Schmiedling I, SvetichWill E, Schmidt R (2012) Effects of repeated insecticide pulses on macroinvertebrate drift in indoor stream mesocosms. Aquat Toxicol 122:56-66

Biocca M, Conte E, Pulcini P, Marinelli E, Pochi D (2011) Sowing simulation tests of a pneumatic drill equipped with systems aimed at reducing the emission of abrasion dust from maize dressed seed. $\mathrm{J}$ Environ Sci Health B 46:438-448

Bloem S, Mizell RF, Bloem KA, Hight SD, Carpenter JE (2005) Laboratory evaluation of insecticides for control of the invasive Cactoblastis cactorum (Lepidoptera: Pyralidae). Fla Entomol 88: 395-400

Boggs CL (2003) Environmental variation, life histories, and allocation. In: Boggs CL, Watt WB, Ehrlich PR (eds) Butterflies: ecology and evolution taking flight. The University of Chicago Press, Chicago, pp 185-206

Bonmatin JM, Moineau I, Charvet R, Colin ME, Fleche C, Bengsch ER et al (2005) Behaviour of imidacloprid in fields: toxicity for honey bees. In: Lichtfourse E, Schwarzbauer J, Robert D (eds) In environmental chemistry: green chemistry and pollutants in ecosystems. Springer, New York, pp 483-494

Bonmatin J-M, Giorio C, Girolami V, Goulson D, Kreutzweiser D, Krupke C, Liess M, Long E, Marzaro M, Mitchell E, Noome D, Simon-Delso N, Tapparo A (2014) Environmental fate and exposure; neonicotinoids and fipronil. Environ Sci Pollut Res. doi:10. 1007/s11356-014-3332-7 (this issue)
Bordereau-Dubois B, List O, Calas-List D, Marques O, Communal PY, Thany SH, Lapied B (2012) Transmembrane potential polarization, calcium influx and receptor conformational state modulate the sensitivity of the imidacloprid-insensitive neuronal insect $\mathrm{nAChR}$ to the neonicotinoid insecticides. J Pharmacol Exp Ther. doi:10.1124/jpet. 111.188060

Bortolotti L, Montanari R, Marcelino J, Medrzycki P, Maini S, Porrini C (2003) Effect of sub-lethal imidacloprid doses on the homing rate and foraging activity of honey bees. Bull Insect 56:63-67

Bosch J, Kemp WP (2006) Bee population returns and cherry yields in an orchard pollinated with Osmia lignaria (Hymenoptera: Megachilidae). J Econ Entomol 99:408-413

Bostanian NJ, Hardman JM, Ventard E, Racette G (2005) The intrinsic toxicity of several neonicotinoids to Lygus lineolaris and Hyaliodes vitripennis, a phytophagous and a predacious mired. Pest Manag Sci 61:991-996

Böttger R, Feibicke M, Schaller J, Dudel G (2013) Effects of low-dosed imidacloprid pulses on the functional role of the caged amphipod Gammarus roeseli in stream mesocosms. Ecotoxicol Environ Saf 93:93-100

Braun G, Bicker G (1992) Habituation of an appetitive reflex in the honeybee. J Neurophysiol 67:588-598

Breeze TD, Bailey AP, Balcombe KG et al (2011) Pollination services in the UK: how important are honeybees? Agric Ecosyst Environ 142: 137-143

Brittain C, Bommarco R, Vighi M, Settele J, Potts SG (2010a) Organic farming in isolated landscapes does not benefit flower-visiting insects and pollination. Biol Conserv 143:1860-1867. doi:10.1016/j. biocon.2010.04.029

Brittain CA, Vighi M, Bommarco R, Settele J, Potts SG (2010b) Impacts of a pesticide on pollinator species richness at different spatial scales. Basic App Ecol 11:106-115

Brooks DR, Bater JE, Clark SJ, Monteith DT, Andrews C, Corbett SJ, Beaumont DA, Chapman JW (2012) Large carabid beetle declines in a United Kingdom monitoring network increases evidence for a widespread loss in insect biodiversity. J Appl Ecol 49:1009-1019

Broznic D, Marinic J, Tota M, Juresic GC, Petkovic O, Milin C (2012) Hysteretic behaviour of imidacloprid sorption-desorption in soils of Croatian coastal regions. Soil Sediment Contam 21:850-871

Brunet JL, Badiou A, Belzunces LP (2005) In vivo metabolic fate of $\left[{ }^{14} \mathrm{C}\right]$-acetamiprid in six biological compartments of the honeybee Apis mellifera L. Pest Manag Sci 61:742-748

Brunner JF, Beers EH, Dunley JE, Doerr M, Granger K (2005) Role of neonicotinyl insecticides in Washington apple integrated pest management. Part I. Control of lepidopteran pests. J Insect Sci 5

Bryden J, Gill RJ, Mitton RAA, Raine NE, Jansen VAA (2013) Chronic sublethal stress causes bee colony failure. Ecol Lett 16:1463-1493

Byrne FJ, Toscano NC (2007) Lethal toxicity of systemic residues of imidacloprid against Homalodisca vitripennis (Homoptera: Cicadellidae) eggs and its parasitoid Gonatocerus ashmeadi (Hymenoptera: Mymaridae). Biol Control 43:130-135

Calderone NW (2012) Insect pollinated crops, insect pollinators and us agriculture: trend analysis of aggregate data for the period 1992 2009. PLoS One 7:e37235. doi:10.1371/journal.pone.0037235

Canadian Council of Ministers of the Environment (2007) Canadian water quality guidelines: IMIDACLOPRID. Scientific supporting document. ISBN 978-1-896997-71-1 PDF

Capowiez Y, Berard A (2006) Assessment of the effects of imidacloprid on the behaviour of two earthworm species (Aporrectodea nocturna and Allolobophora icterica) using 2D terraria. Ecotoxicol Environ Saf 64:198-206

Capowiez Y, Rault M, Mazzia C, Belzunces L (2003) Earthworm behaviour as a biomarker - a case study using imidacloprid. Pedobiologia 47:542-547

Capowiez Y, Rault M, Costagliola G, Mazzia C (2005) Lethal and sublethal effects of imidacloprid on two earthworm species 
(Aporrectodea nocturna and Allolobophora icterica). Biol Fertil Soils 41:135-143

Capowiez Y, Bastardie F, Costagliola G (2006) Sublethal effects of imidacloprid on the burrowing behaviour of two earthworm species: modifications of the 3D burrow systems in artificial cores and consequences on gas diffusion in soil. Soil Biol Biochem 38:285-293

Capowiez Y, Dittbrenner N, Rault M, Triebskorn R, Hedde M, Mazzia C (2010) Earthworm cast production as a new behavioural biomarker for toxicity testing. Environ Pollut 158:388-393

Casida JE (2011) Neonicotinoid metabolism: compounds, substituents, pathways, enzymes, organisms, and relevance. J Agric Food Chem 59:2923-2931

Chagnon M, Gingras J, de Oliveira D (1993) Complementary aspects of strawberry pollination by honey and indigenous bees (Hymenoptera). J Econ Entomol 86:416-420

Charmillot PJ, Pasquier D, Salamin C, Ter-Hovannesyan A (2007) Ovicidal and larvicidal effectiveness of insecticides applied by dipping apples on the small fruit tortrix Grapholita lobarzewskii. Pest Manag Sci 63:677-681

Charpentier G, Louat F, Bonmatin JM, Marchand PA, Vannier F, Locker D, Decoville M (2014) Lethal and sublethal effects of imidacloprid, after chronic exposure, on the insect model Drosophila melanogaster. Environ Sci Technol 48(7):4096-4102

Chen RZ, Klein MG (2012) Efficacy of insecticides against the rice stemborer, Chilo suppressalis (Walker) (Lepidoptera: Crambidae), and use of sex pheromones to time accurately the yearly application. Int $\mathrm{J}$ Pest Manag 58:353-359

Chen XD, Culbert E, Herbert V, Stark JD (2010) Mixture effects of the adjuvant R-11 and the insecticide imidacloprid on population growth rate and other parameters of Ceriodaphnia dubia. Ecotoxicol Environ Saf 73:132-137

Cheng XA, Chang C, Dai SM (2010) Responses of striped stem borer, Chilo suppressalis (Lepidoptera: Pyralidae), from Taiwan to a range of insecticides. Pest Manag Sci 66:762-766

Chowdhury S, Mukhopadhyay S, Bhattacharyya A (2012) Degradation dynamics of the insecticide: Clothianidin (Dantop 50\% WDG) in a tea field ecosystem. Bull Environ Contam Toxicol 89:340-343

Cichon LB, Soleno J, Anguiano OL, Garrido SA, Montagna CM (2013) Evaluation of cytochrome P450 activity in field populations of Cydia pomonella (Lepidoptera: Tortricidae) resistant to azinphosmethyl, acetamiprid, and thiacloprid. J Econ Entomol 106:939-944

Coleman DC, Ingham ER (1988) Carbon, nitrogen, phosphorus and sulphur cycling in terrestrial ecosystems. Biogeochemistry 5:3-6

Colin ME, Bonmatin JM, Moineau I, Gaimon C, Brun S, Vermandere JP (2004) A method to quantify and analyze the foraging activity of honey bees: relevance to the sublethal effects induced by systemic insecticides. Arch Environ Contam Toxicol 47:387-395

Couvillon MJ, Barton SN, Cohen JA, Fabricius OK, Kaercher MH, Cooper LS, Silk MJ, Helantera H, Ratnieks FLW (2010) Alarm pheromones do not mediate rapid shifts in honey bee guard acceptance threshold. J Chem Ecol 36:1306-1308

Cox L, Koskinen WC, Yen PY (1997) Sorption-desorption of imidacloprid and its metabolites in soils. J Agric Food Chem 45: $1468-1472$

Cox L, Hermosin MC, Cornejo J (2004) Influence of organic amendments on sorption and dissipation of imidacloprid in soils. Int $\mathrm{J}$ Environ Anal Chem 84:95-102

Cresswell JE (2011) A meta-analysis of experiments testing the effects of neonicotinoid insecticide (imidacloprid) on honey bees. Ecotoxicology 20:149-154

Cresswell JE, Thompson H (2012) Comment on "A common pesticide decreases foraging success and survival in honey bees". Science $337: 1453$

Cresswell JE, Desneux N, van Engelsdorp D (2012a) Dietary traces of neonicotinoid pesticides as a cause of population declines in honey bees: an evaluation by Hill's epidemiological criteria. Pest Manag Sci 68:819-827

Cresswell JE, Page CJ, Uygun MB, Holmbergh M, Li Y, Wheeler JG, Laycock I, Pook CJ, De Ibarra NH, Smirnoff N, Tyler CR (2012b) Differential sensitivity of honey bees and bumble bees to a dietary insecticide (imidacloprid). Zoology 115:365-371

Cutler GC, Scott-Dupree C (2007) Exposure to clothianidin seed-treated canola has no long-term impact on honey bees. J Econ Entomol 100: 765-772

Davis BNK, Lakhani KH, Yates TJ (1991a) The hazards of insecticides to butterflies of field margins. Agric Ecosyst Environ 36:151-161

Davis BNK, Lakhani KH, Yates TJ, Frost AJ (1991b) Bioassays of insecticide spray drift: the effects of wind speed on the mortality of Pieris brassicae larvae (Lepidoptera) caused by diflubenzuron. Agric Ecosyst Environ 36:141-149

Davis BNK, Lakhani KH, Yates TJ, Frost AJ, Plant RA (1993) Insecticide drift from ground-based, hydraulic spraying of peas and brussels sprouts: bioassays for determining buffer zones. Agric Ecosyst Environ 43:93-108

Decourtye A, Devillers J (2010) Ecotoxicology of neonicotinoids insecticides in the bees. In: Thany S (ed) Insect nicotinic acetylcholine receptors. Landes Bioscience, St. Austin

Decourtye A, Lacassie E, Pham-Delegue MH (2003) Learning performances of honeybees (Apis mellifera L.) are differentially affected by imidacloprid according to the season. Pest Manag Sci 59:269-278

Decourtye A, Armengaud C, Renou M, Devillers J, Cluzeau S, Gauthier M, Pham-Delègue MH (2004a) Imidacloprid impairs memory and brain metabolism in the honeybee (Apis mellifera L.). Pestic Biochem Physiol 78:83-92

Decourtye A, Devillers J, Cluzeau S, Charreton M, Pham-Delègue MH (2004b) Effects of imidacloprid and deltamethrin on associative learning in honeybees under semi-field and laboratory conditions. Ecotoxicol Environ Saf 57:410-419

Decourtye A, Devillers J, Genecque E, Le Menach K, Budzinski H, Cluzeau S, Pham-Delegue MH (2005) Comparative sublethal toxicity of nine pesticides on olfactory learning performances of the honeybee Apis mellifera. Arch Environ Contam Toxicol 48:242-250

Decourtye A, Mader E, Desneux N (2010) Landscape enhancement of floral resources for honey bees in agro-ecosystems. Apidologie 41: 264-277

DEFRA (2007) Assessment of the risk posed to honeybees by systemic pesticides. PS2322, CSL York, UK

DEFRA (2009) Intermittent exposure in terrestrial invertebrates - a case study with honeybees. PS2341, CSL York, UK

Déglise P, Grünewald B, Gauthier M (2002) The insecticide imidacloprid is a partial agonist of the nicotinic receptor of honeybee Kenyon cells. Neurosci Lett 321:13-16

Delbeke E, Vercruysse P, Tirry L, de Clercq P, Degheele D (1997) Toxicity of diflubenzuron, pyriproxyfen, imidacloprid and diafenthiuron to the predatory bug Orius laevigatus (Het.: Anthocoridae). Entomophaga 42:349-358

Derecka K, Blythe MJ, Malla S, Genereux DP, Guffanti A, Pavan P, Moles A, Snart C, Ryder T, Ortori CA, Barrett DA, Schuster E, Stöger R (2013) Transient exposure to low levels of insecticide affects metabolic networks of honeybee larvae. PLoS One 8:e68191

Desneux N, Decourtye A, Delpuech JM (2007) The sublethal effects of pesticides on beneficial arthropods. Ann Rev Entomol 52:81-106

Detzel A, Wink M (1993) Attraction, deterrence or intoxication of bees (Apis mellifera) by plant allelochemicals. Chemoecology 4:8-18

Di Prisco G, Cavaliere V, Annoscia D, Varricchio P, Caprio E, Nazzi F, Gargiulo G, Pennacchio F (2013) Neonicotinoid clothianidin adversely affects insect immunity and promotes replication of a viral pathogen in honey bees. Proc Natl Acad Sci U S A 110:1846618471. doi:10.1073/pnas. 1314923110

Diez-Rodrijguez GI, de Baptista GC, Trevizani LR, Haddad ML, Nava DE (2006) Residues of thiamethoxam, aldicarb and its metabolites 
in coffee leaves and effect on the control of Leucoptera coffeella (Guerin-Meneville) (Lepidoptera: Lyonetiidae). Neotropical Entomol 35:257-263

Dilling C, Lambdin P, Grant J, Rhea R (2009) Community response of insects associated with eastern hemlock to imidacloprid and horticultural oil treatments. Environ Entomol 38:53-66

Dittbrenner N, Triebskorn R, Moser I, Capowiez Y (2010) Physiological and behavioural effects of imidacloprid on two ecologically relevant earthworm species (Lumbricus terrestris and Aporrectodea caliginosa). Ecotoxicology 19:1567-1573

Dittbrenner N, Schmitt H, Capowiez Y, Triebskorn R (2011a) Sensitivity of Eisenia fetida in comparison to Aporrectodea caliginosa and Lumbricus terrestris after imidacloprid exposure. Body mass change and histopathology. J Soils Sediments 11:1000-1010

Dittbrenner N, Moser I, Triebskorn R, Capowiez Y (2011b) Assessment of short and long-term effects of imidacloprid on the burrowing behaviour of two earthworm species (Aporrectodea caliginosa and Lumbricus terrestris) by using 2D and 3D post-exposure techniques. Chemosphere 84:1349-1355

Dittbrenner N, Capowiez Y, Kohler H, Triebskorn R (2012) Stress protein response (Hsp70) and avoidance behaviour in Eisenia fetida, Aporrectodea caliginosa, and Lumbricus terrestris when exposed to imidacloprid. J Soils Sediments 12:198-206

Dively G, Hooks C (2010) Use patterns of neonicotinoid insecticides on cucurbit crops and their potential exposure to honey bees. Progress report, strategic agricultural initiative grants program, EPA region 3

Doffou NM, Ochou OG, Kouassi P (2011) Susceptibility of Pectinophora gossypiella (Lepidoptera: Gelechiidae) and Cryptophlebia leucotreta (Lepidoptera: Tortricidae) to insecticides used on cotton crops in Côte d'Ivoire, West Africa. Implications in insecticide resistance pest management strategies. Resistant Pest Manag Newsl 20:10-15

Dogramaci M, Tingey WM (2008) Comparison of insecticide resistance in a North American field population and a laboratory colony of potato tuberworm (Lepidoptera: Gelechiidae). J Pest Sci 81:17-22

Dondero F, Negri A, Boatti L, Marsano F, Mignone F, Viarengo A (2010) Transcriptomic and proteomic effects of a neonicotinoid insecticide mixture in the marine mussel (Mytilus galloprovincialis, Lam.). Sci Total Environ 15:3775-3786

Donnarumma L, Pulcini P, Pochi D, Rosati S, Lusco L, Conte E (2011) Preliminary study on persistence in soil and residues in maize of imidacloprid. J Environ Sci Health B 46:469-472

Dunley JE, Brunner JF, Doerr MD, Beers EH (2006) Resistance and cross-resistance in populations of the leafrollers, Choristoneura rosaceana and Pandemis pyrusana, in Washington apples. J Insect Sci 6

Dupuis JP, Gauthier M, Raymond-Delpech V (2011) Expression patterns of nicotinic subunits alpha 2 , alpha 7 , alpha 8 , and beta 1 affect the kinetics and pharmacology of ACh-induced currents in adult bee olfactory neuropiles. J Neurophysiol 106:1604-1613

Durham EW, Scharf ME, Siegfried BD (2001) Toxicity and neurophysiological effects of fipronil and its oxidative sulfone metabolite on European corn borer larvae (Lepidoptera: Crambidae). Pestic Biochem Physiol 71:97-106

Durham EW, Siegfried BD, Scharf ME (2002) In vivo and in vitro metabolism of fipronil by larvae of the European corn borer Ostrinia nubilalis. Pest Manag Sci 58:799-804

Easton AH, Goulson D (2013) The neonicotinoid insecticide imidacloprid repels pollinating flies and beetles at field-realistic concentrations. PLoS One 8:e54819

Edwards CA, Bohlen PJ (1996) Biology and ecology of earthworms, 3rd edn. Chapman and Hall, London

EFSA (2006) Draft Assessment Report (DAR). Draft assessment report: initial risk assessment provided by the rapporteur member State Germany for the existing active substance imidacloprid
Eisenback BM, Salom SM, Kok LT, Lagalante AF (2010) Lethal and sublethal effects of imidacloprid on Hemlock woolly Adelgid (Hemiptera: Adelgidae) and two introduced predator species. J Econ Entomol 103:1222-1234

El Hassani AK, Dacher M, Gauthier M, Armengaud C (2005) Effects of sublethal doses of fipronil on the behavior of the honeybee (Apis mellifera). Pharmacol Biochem Behav 82:30-39

El Hassani AK, Dacher M, Gary V, Lambin M, Gauthier M, Armengaud C (2008) Effects of sublethal doses of acetamiprid and thiamethoxam on the behavior of the honeybee (Apis mellifera). Arch Environ Contam Toxicol 54:653-661

El Hassani AK, Dupuis JP, Gauthier M, Armengaud C (2009) Glutamatergic and GABAergic effects of fipronil on olfactory learning and memory in the honeybee. Invert Neurosci 9:91-100

Elbert A, Becker B, Hartwig J, Erdelen C (1991) Imidacloprid - a new systemic insecticide. Plant Prot Nachr Bayer 44:113-136

Epstein LH, Robinson JL, Roemmich JN, Marusewski A (2011) Slow rates of habituation predict greater zBMI gains over 12 months in lean children. Eat Behav 12:214-218

European Comission (2010) Commission Directive 2010/21/EU of 12 March 2010 amending Annex I to Council Directive 91/414/EEC as regards the specific provisions relating to clothianidin, thiamethoxam, fipronil and imidacloprid

Fagin D (2012) The learning curve. Nature 490:462-465. doi:10.1038/ $490462 \mathrm{a}$

Fang Q, Huang CH, Ye GY, Yao HW, Cheng JA et al (2008) Differential fipronil susceptibility and metabolism in two rice stem borers from China. J Econ Entomol 101:1415-1420

Farooqui T (2013) A potential link among biogenic amines based pesticides, learning and memory, and colony collapse disorder: a unique hypothesis. Neurochem Int 62:122-136

Faucon JP, Aurieres C, Drajnudel P, Mathieu L, Ribiere M, Martel AC, Zeggane S, Chauzat MP, Aubert MFA (2005) Experimental study on the toxicity of imidacloprid given in syrup to honey bee (Apis mellifera) colonies. Pest Manag Sci 61:111-125

Feber RE, Firbank LG, Johnson PJ, Macdonald DW (1997) The effects of organic farming on pest and non-pest butterfly abundance. Agric Ecosyst Environ 64:133-139

Feltham H, Park K, Goulson D (2014) Field realistic doses of pesticide imidacloprid reduce bumblebee pollen foraging efficiency. Ecotoxicology 37:301-308

Fischer J, Müller T, Spatz A-K, Greggers U, Grünewald B et al (2014) Neonicotinoids interfere with specific components of navigation in honeybees. PLoS One 9:e91364

Ford KA, Casida JE (2006) Unique and common metabolites of thiamethoxam, clothianidin, and dinotefuran in mice. Chem Res Toxicol 19:1549-1556

Fossen M (2006) Environmental fate of imidacloprid. Environmental monitoring department of pesticide regulation, California, USA

Franklin MT, Winston ML, Morandin LA (2004) Effects of clothianidin on Bombus impatiens (Hymentoptera: Apidae) colony health and foraging behaviour. J Econ Entomol 97:369-373

Frantzios G, Paptsiki K, Sidiropoulou B, Lazaridis G, Theophilidis G, Mavragani-Tsipidou P (2008) Evaluation of insecticidal and genotoxic effects of imidacloprid and acetochlor in Drosophila melanogaster. J Appl Entomol 132:583-590

Freemark K, Boutin C (1995) Impacts of agricultural herbicide use on terrestrial wildlife in temperate landscapes: a review with special reference to North America. Agric Ecosyst Environ 52:67-91

Funayama K, Ohsumi S (2007) Control effect of neonicotinoid insecticides on apple leaf miner, Phyllonorycter ringoniella (Lepidoptera: Gracillariidae). Annu Rep Soc Plant Protect N Jpn 58:156-158

Galvanho JP, Carrera MP, Moreira DDO, Erthal M, Silva CP, Samuels RI (2013) Imidacloprid inhibits behavioral defences of the leaf-cutting ant Acromyrmex subterraneus subterraneus (Hymenoptera: 
Formicidae). J Insect Behav 26:1-13. doi:10.1007/S10905-0129328-6

Gauthier M (2010) State of the art on insect nicotinic acetylcholine receptor function in learning and memory. In: Thany $\mathrm{S}$ (ed) Insect nicotinic acetylcholine receptors. Springer, Berlin

Gawleta N, Zimmermann Y, Eltz T (2005) Repellent foraging scent recognition across bee families. Apidologie 36:325-330

Geiger F, Bengtsson J, Berendse F, Weisser WW, Emmerson M, Morales MB, Ceryngier P, Liira J, Tscharntke T, Winqvist C, Eggers S, Bommarco R, Pärt T, Bretagnolle V, Plantegenest M, Clement LW, Dennis C, Palmer C, Oñate JJ, Guerrero I, Hawro V, Aavik T, Thies C, Flohre A, Hänke S, Fischer C, Goedhart PW, Inchausti P (2010) Persistent negative effects of pesticides on biodiversity and biological control potential on European farmland. Basic Appl Ecol 11:97105

Gill RJ, Ramos-Rodriguez O, Raine NE (2012) Combined pesticide exposure severely affects individual- and colony-level traits in bees. Nature 491:105-108

Girolami V, Mazzon L, Squartini A, Mori N, Marzaro M, Bernardo AD, Tapparo A (2009) Translocation of neonicotinoid insecticides from coated seeds to seedling guttation drops: a novel way of intoxication for bees. J Econ Entomol 102:1808-1815

Girolami V, Marzaro M, Vivan L, Mazzon L, Greatti M, Giorio C, Marton D, Tapparo A (2012) Fatal powdering of bees in flight with particulates of neonicotinoids seed coating and humidity implication. J Appl Entomol 136:17-26

Giurfa M (1993) The repellent scent-mark of the honeybee Apis mellifera ligustica and its role as communication cue during foraging. Insect Soc 40:59-67

Gomez-Eyles JL, Svendsen C, Lister L, Martin H, Hodson ME, Spurgeon DJ (2009) Measuring and modelling mixture toxicity of imidacloprid and thiacloprid on Caenorhabditis elegans and Eisenia fetida. Ecotoxicol Environ Saf 72:71-79

Goulson D (2003) Effects of introduced bees on native ecosystems. Annu Rev Ecol Evol Syst 34:1-26

Goulson D (2010) Bumblebees: behaviour, ecology and conservation. Oxford University Press, Oxford

Goulson D, Chapman JW, Hughes WOH (2001) Discrimination of unrewarding flowers by bees; direct detection of rewards and use of repellent scent marks. J Insect Behav 14:669-678

Gradish AE, Scott-Dupree CD, Shipp L, Harrisa CR, Ferguson G (2010) Effect of reduced risk pesticides for use in greenhouse vegetable production on Bombus impatiens (Hymenoptera: Apidae). Pest Manag Sci 66:142-146

Graystock P, Yates K, Darvill B, Goulson D, Hughes WOH (2013a) Emerging dangers: deadly effects of an emergent parasite in a new pollinator host. J Invertebr Pathol 114:114-119

Graystock P, Yates K, Evison S, Darvill B, Goulson D, Hughes WOH (2013b) The Trojan hives: pollinator pathogens, imported and distributed in bumblebee colonies. J Appl Ecol 50:1207-1215

Greatti M, Sabatini AG, Barbattini R, Rossi S, Stravisi A (2003) Risk of environmental contamination by the active ingredient imidacloprid used for corn seed dressing. Preliminary results. Bull Insect 56:69-72

Greenleaf S, Kremen C (2006) Wild bees enhance honey bees' pollination of hybrid sunflower. Proc Natl Acad Sci U S A 103:13890 13895

Gregorc A, Ellis JD (2011) Cell death localization in situ in laboratory reared honey bee (Apis mellifera L.) larvae treated with pesticides. Pestic Biochem Physiol 99:200-207

Gross M (2008) Pesticides linked to bee deaths. Curr Biol Vol 18:684

Guez D, Suchail S, Gauthier M, Maleszka R, Belzunces LP (2001) Contrasting effects of imidacloprid on habituation in 7- and 8-day-old honeybees (Apis mellifera). Neurobiol Learn Mem 76:183-191

Guez D, Belzunces LP, Maleszka R (2003) Effects of imidacloprid metabolites on habituation in honeybees suggest the existence of two subtypes of nicotinic receptors differentially expressed during adult development. Pharmacol Biochem Behav 75:217-222

Gupta S, Gajbhiye VT (2007) Persistence of acetamiprid in soil. Bull Environ Contam Toxicol 78:349-352

Han P, Niu CY, Lei CL, Cui JJ, Desneux N (2010) Use of an innovative Ttube maze assay and the proboscis extension response assay to assess sublethal effects of GM products and pesticides on learning capacity of the honey bee Apis mellifera L. Ecotoxicology 19:1612-1619

Hatjina F, Papaefthimiou C, Charistos L, Dogaroglu T, Bouga M, Emmanouil C, Arnold G (2013) Sublethal doses of imidacloprid decreased size of hypopharyngeal glands and respiratory rhythm of honeybees in vivo. Apidologie 44:467-480

Hayasaka D, Korenaga T, Suzuki K, Saito F, Sánchez-Bayo F, Goka K (2012) Cumulative ecological impacts of two successive annual treatments of imidacloprid and fipronil on aquatic communities of paddy mesocosms. Ecotoxicol Environ Saf 80:355-62. doi:10. 1016/j.ecoenv.2012.04.004

Haynes KF (1988) Sublethal effects of neurotoxic insecticides on insect behavior. Annu Rev Entomol 33:149-168

He YP, Gao CF, Cao MZ, Chen WM, Huang LQ et al (2007) Survey of susceptibilities to monosultap, triazophos, fipronil, and abamectin in Chilo suppressalis (Lepidoptera: Crambidae). J Econ Entomol 100: 1854-1861

He YP, Gao CF, Chen WM, Huang LQ, Zhou WJ et al (2008) Comparison of dose responses and resistance ratios in four populations of the rice stem borer, Chilo suppressalis (Lepidoptera: Pyralidae), to 20 insecticides. Pest Manag Sci 64:308-315

He YP, Zhang JF, Gao CF, Su JY, Chen JM et al (2013) Regression analysis of dynamics of insecticide resistance in field populations of Chilo suppressalis (Lepidoptera: Crambidae) during 2002-2011 in China. J Econ Entomol 106:1832-1837

Henry M, Beguin M, Requier F, Rollin O, Odoux JF, Aupinel P, Aptel J, Tchamitchian S, Decourtye A (2012a) A common pesticide decreases foraging success and survival in honey bees. Science 336 : 348-350

Henry M, Beguin M, Requier F, Rollin O, Odoux J, Aupinel P, Aptel J, Tchamitchian S, Decourtye A (2012b) Response to comment on "A common pesticide decreases foraging success and survival in honey bees". Science 337:1453

Hill TA, Foster RE (2000) Effect of insecticides on the diamondback moth (Lepidoptera: Plutellidae) and its parasitoid Diadegma insulare (Hymenoptera: Ichneumonidae). J Econ Entomol 93:763768

Hoi KK, Daborn PJ, Battlay P, Robin C, Batterham P, O'Hair RA, Donald WA (2014) Dissecting the insect metabolic machinery using twin ion mass spectrometry: a single P450 enzyme metabolizes the insecticide imidacloprid in vivo. Anal Chem 86(7):3525-3532

Huang SJ, Xu JF, Han ZJ (2006) Baseline toxicity data of insecticides against the common cutworm Spodoptera litura (Fabricius) and a comparison of resistance monitoring methods. Int J Pest Manag 52: 209-213

Illarionov AI (1991) Toxic effect of some insecticides on the honeybee. Agrokhimiva 8:121-125

Iwasa T, Motoyama N, Ambrose JT, Roe MR (2004) Mechanism for the differential toxicity of neonicotinoid insecticides in the honey bee, Apis mellifera. Crop Prot 23:371-378

James DG, Price TS (2002) Fecundity in twospotted spider mite (Acari: Tetranychidae) is increased by direct and systemic exposure to imidacloprid. J Econ Entomol 95:729-732

Jeschke P, Nauen R, Schindler M, Elbert A (2010) Overview of the status and global strategy for neonicotinoids. J Agric Food Chem 59: 2897-2908

Jinguji H, Thuyet DQ, Uéda T, Watanabe H (2013) Effect of imidacloprid and fipronil pesticide application on Sympetrum infuscatum (Libellulidae: Odonata) larvae and adults. Paddy Water Environ $11: 277-284$ 
Jones MM, Robertson JL, Weinzierl RA (2010) Susceptibility of Oriental fruit moth (Lepidoptera: Tortricidae) larvae to selected reduced-risk insecticides. J Econ Entomol 103:1815-1820

Jones MM, Robertson JL, Weinzierl RA (2012) Toxicity of thiamethoxam and mixtures of chlorantraniliprole plus acetamiprid, esfenvalerate, or thiamethoxam to neonates of oriental fruit moth (Lepidoptera: Tortricidae). J Econ Entomol 105:1426-1431

Kalajdzic P, Oehler S, Reczko M, Pavlidi N, Vontas J, Hatzigeorgiou AG, Savakis C (2012) Use of mutagenesis, genetic mapping and next generation transcriptomics to investigate insecticide resistance mechanisms. PLoS One 7:e40296. doi:10.1371/journal.pone. 0040296

Kalajdzic P1, Markaki M, Oehler S, Savakis C (2013) Imidacloprid does not induce Cyp genes involved in insecticide resistance of a mutant Drosophila melanogaster line. Food Chem Toxicol 60:355-359. doi:10.1016/j.fct.2013.07.080

Kather R, Drijfhout FP, Martin SJ (2011) Task group differences in cuticular lipids in the honey bee Apis mellifera. J Chem Ecol 37: 205-212

Khani A, Ahmadi F, Ghadamyari M (2012) Side effects of imidacloprid and abamectin on the Mealybug destroyer, Cryptolaemus montrouzieri. Trakia J Sci 10:30-35

Kilpatrick AL, Hagerty AM, Turnipseed SG, Sullivan MJ, Bridges WC (2005) Activity of selected neonicotinoids and dicrotophos on nontarget arthropods in cotton: implications in insect management. J Econ Entomol 98:814-820

Kinkler H, Löser S, Rehnelt K (1987) 10 Jahre Erforschung des Moselapollofalters (Parnassius apollo vinningensis STICHEL 1899, Lepidoptera, Papilionidae) im modernen Weinbaugebiet der Mosel-ein Beitrag zu seiner Rettung. Commun Assoc rheinischwestfälischer Lepidopterologen 5:74-96

Klein AM, Vaissie're BE, Cane JH, Steffan-Dewenter I, Cunningham SA, Kremen C, Tscharntke T (2007) Importance of pollinators in changing landscapes for world crops. Proc R Soc B 274:303-313

Kluser S, Neumann P, Chauzat MP, Pettis JS (2011) UNEP emerging issues: global honey bee colony disorder and other threats to insect pollinators. http://www.unep.org. Accessed 25 October 2012

Knight AL (2010) Cross-resistance between azinphos-methyl and acetamiprid in populations of codling moth, Cydia pomonella (L.) (Lepidoptera: Tortricidae), from Washington State. Pest Manag Sci 66:865-874

Knight ME, Martin AP, Bishop S, Osborne JL, Hale RJ, Sanderson RA, Goulson D (2005) An interspecific comparison of foraging range and nest density of four bumblebee (Bombus) species. Mol Ecol 14: $1811-1820$

Knoepp JD, Vose JM, Michael JL, Reynolds BC (2012) Imidacloprid movement in soils and impacts on soil microarthropods in Southern Appalachian eastern hemlock stands. J Environ Qual 41:469-478

Knollengberg WG, Merritt RW, Lawson DL (1985) Consumption of leaf litter by Lumbricus terrestris (Oligochaeta) on a Michigan woodland floodplain. Am Midl Nat J 113:1-6

Kramarz P, Stark JD (2003) Population level effects of cadmium and the insecticide, imidacloprid to the Parasitoid, Aphidius ervi after exposure through its host, the pea aphid, Acyrthosiphon pisum. Biol Control 27:310-314

Kreutzweiser DP, Sibley PK (2013) Aquatic communities: pesticide impacts. In: Jorgensen SE (ed) Encyclopedia of environmental management. Taylor and Francis, New York, pp 312-321

Kreutzweiser DP, Good KP, Chartrand DT, Scarr TA, Thompson DG (2008a) Are leaves that fall from imidacloprid-treated maple trees to control Asian longhorned beetles toxic to non-target decomposer organisms? J Environ Qual 37:639-646

Kreutzweiser DP, Good KP, Chartrand DT, Scarr TA, Holmes SB, Thompson DG (2008b) Effects on litter-dwelling earthworms and microbial decomposition of soil-applied imidacloprid for control of wood-boring insects. Pest Manag Sci 64:112-118
Kreutzweiser DP, Thompson DG, Scarr TA (2009) Imidacloprid in leaves from systemically treated trees may inhibit litter breakdown by nontarget invertebrates. Ecotoxicol Environ Saf 72:1053-1057

Krischik VA, Landmark AL, Heimpel GE (2007) Soil-applied imidacloprid is translocated to nectar and kills nectar-feeding Anagyrus pseudococci (Girault) (Hymenoptera: Encyrtidae). Environ Entomol 36:1238-1245

Kromp B (1999) Carabid beetles in sustainable agriculture: a review on pest control efficacy, cultivation impacts and enhancement. Agric Ecosyst Environ 74:187-228

Krupke CH, Hunt GJ, Eitzer BD, Andino G, Given K (2012) Multiple routes of pesticide exposure for honey bees living near agricultural fields. PLoS One 7:e29268

Kullik SA, Sears MK et al (2011) Sublethal effects of Cry 1F Bt corn and clothianidin on black cutworm (Lepidoptera: Noctuidae) larval development. J Econ Entomol 104:484-93

Kunkel BA, Held DW, Potter AD (1999) Impact of halofenozide, imidacloprid, and bendiocarb on beneficial invertebrates and predatory activity in turfgrass. J Econ Entomol 92:922-930

Kunkel BA, Held DW, Potter DA (2001) Lethal and sub-lethal effects of bendiocarb, halofenozide, and imidacloprid on Harpalus pennysylvanicus (Coleoptera: Carabidae) following different modes of exposure in turfgrass. J Econ Entomol 94:60-67

Kurwadkar ST, Dewinne D, Wheat R, McGahan DG, Mitchell FL (2013) Time dependent sorption behaviour of dinotefuran, imidacloprid and thiamethoxam. J Environ Sci Health B 48:237-242

Lambin M, Armengaud C, Raymond S, Gauthier M (2001) Imidaclopridinduced facilitation of the proboscis extension reflex habituation in the honeybee. Arch Insect Biochem Physiol 48:129-134

Landis DA, Wratten SD, Gurr GM (2000) Habitat management to conserve natural enemies of arthropod pests in agriculture. Annu Rev Entomol 45:175-201

Larson JL, Redmond CT, Potter DA (2012) Comparative impact of an anthranilic diamide and other insecticidal chemistries on beneficial invertebrates and ecosystem services in turfgrass. Pest Manag Sci 68:740-748

Laycock I, Lenthall KM, Barratt AT, Cresswell JE (2012a) Effects of imidacloprid, a neonicotinoid pesticide, on reproduction in worker bumble bees (Bombus terrestris). Ecotoxicology 21:1937-1945

Laycock I, Lenthall KM, Barratt AT, Cresswell JE (2012b) Erratum to: Effects of imidacloprid, a neonicotinoid pesticide, on reproduction in worker bumble bees (Bombus terrestris). Ecotoxicology 21: 1946-1946

LeBlanc HMK, Culp JM, Baird DJ, Alexander AC, Cessna AJ (2012) Single versus combined lethal effects of three agricultural insecticides on larvae of the freshwater insect Chironomus dilutes. Arch Environ Contam Toxicol 63:378-390

Lee KW (1985) Earthworms: their ecology and relationship with soils and land use. Academic, Sydney

Lee JC, Menalled FD, Landis DA (2001) Refuge habitats modify impact of insecticide disturbance on carabid beetle communities. J Appl Ecol 38:472-483

Li AG, Yang YH, Wu SW, Li C, Wu YD (2006) Investigation of resistance mechanisms to fipronil in diamondback moth (Lepidoptera: Plutellidae). J Econ Entomol 99:914-919

Li XT, Huang QC, Yuan JZ, Tang ZH (2007) Fipronil resistance mechanisms in the rice stem borer, Chilo suppressalis Walker. Pestic Biochem Physiol 89:169-174

Liang GM, Chen W, Liu TXTX (2003) Effects of three neem-based insecticides on diamondback moth (Lepidoptera: Plutellidae). Crop Prot 22:333-340

Liess M, Beketov M (2011) Traits and stress-keys to identify community effects at low toxicant level. Ecotoxicology 20:1328-1340

Liess M, Beketov MA (2012) Rebuttal related to "Traits and stress - keys to identify community effects of low levels of toxicants in test systems". Ecotoxicology 21:300-303 
Liess M, von der Ohe PC (2005) Analyzing effects of pesticides on invertebrate communities in streams. Environ Toxicol Chem 24: 954-965

Liess M, Schäfer RB, Schriever CA (2008) The footprint of pesticide stress in communities - species traits reveal community effects of toxicants. Sci Total Environ 406:484-90

Liess M, Foit K, Becker A, Hassold E, Dolciotti I, Kattwinkel M, Duquesne S (2013) Culmination of low-dose pesticide effects. Environ Sci Tech 47:8862-8868

Lintott DR (1992) NTN 33893 (240 FS formulation): acute toxicity to the mysid, Mysidopsis bahia, under flow-through conditions. Toxicon Environmental Sciences, Jupiter, Florida (performing laboratory). Miles Incorporated, Kansas City, Missouri (submitting company). 43 pp. Miles Report No. 103845

Little EE (1990) Behavioural toxicology; stimulating challenges for a growing discipline. Environ Toxicol Chem 9:1-2

Longley M, Sotherton NW (1997) Factors determining the effects of pesticides upon butterflies inhabiting arable farmland. Agric Ecosyst Environ 61:1-12

Lucas E, Giroux S, Demougeot S, Duchesne RM, Coderre D (2004) Compatibility of a natural enemy, Coleomegilla maculata lengi (Col., Coccinellidae) and four insecticides used against the Colorado potato beetle (Col., Chrysomelidae). J Appl Entomol 128:233-239

Lukancic S, Zibrat U, Mezek T, Jerebic A, Simcic T, Brancelj A (2010) Effects of exposing two non-target crustacean species, Asellus aquaticus L., and Gammarus fossarum Koch., to atrazine and imidacloprid. Bull Environ Contam Toxicol 84(1):85-90. doi:10. 1007/s00128-009-9854-x

Luo Y, Zang Y, Zhong Y, Kong Z (1999) Toxicological study of two novel pesticides on earthworm Eisenia fetida. Chemosphere 39: 2347-2356

Lydy M, Belden J, Wheelock C, Hammock B, Denton D (2004) Challenges in regulating pesticide mixtures. Ecol Soc 9:1

Magalhaes LC, Walgenbach JF (2011) Life stage toxicity and residual activity of insecticides to codling moth and Oriental fruit moth (Lepidoptera: Tortricidae). J Econ Entomol 104:1950-1959

Maisonnasse A, Lenoir JC, Beslay D, Crauser D, Le Conte Y (2010) E-bOcimene, a volatile brood pheromone involved in social regulation in the honey bee colony (Apis mellifera). PLoS One 5

Mani S, Medrzycki P, Porrini C (2010) The puzzle of honey bee losses: a brief review. Bull Insect 63:153-160

Mann RS, Uppal SK, Sharma S, Mann KK (2009) Soil efficacy of fipronil to early stage pests of sugarcane, and its effect on development on Chilo infuscatellus Snellen (Crambidae: Lepidoptera). Int J Pest Manag 55:307-315

Marzaro M, Vivan L, Targa A, Mazzon L, Mori N, Greatti M, Petrucco Toffolo E, Di Bernardo A, Giorio C, Marton D, Tapparo A, Girolami V (2011) Lethal aerial powdering of honey bees with neonicotinoids from fragments of maize seed coat. Bull Insect 64:118-125

Mason R, Tennekes HA, Sanchez-Bayo F, Jepsen PU (2013) Immune suppression by neonicotinoid insecticides at the root of global wildlife declines. J Environ Immunol Toxicol 1:3-12

Maus C, Nauen R (2010) Response to the publication: Tennekes H.A. The significance of the Druckey-Küpfmüller equation for risk assessment - the toxicity of neonicotinoid insecticides is reinforced by exposure time. Toxicology 280:176-177. doi:10.1016/j.tox.2010. 11.014

Maxim L, van der Sluijs JP (2007) Uncertainty: cause or effect of stakeholders' debates? Analysis of a case study: the risk for honeybees of the insecticide Gaucho ${ }^{\circledR}$. Sci Total Environ 376:1-17

Maxim L, van der Sluijs JP (2013) Seed-dressing systemic insecticides and honeybees, chapter 16. In: European Environment Agency (ed.) Late lessons from early warnings: science, precaution, innovation. European Environment Agency (EEA) report 1/2013, Copenhagen. p. $401-438$
Mayer DF, Lunden JD (1997) Effects of imidacloprid insecticide on three bee pollinators. Hortic Sci 29:93-97

McKern JA, Johnson DT, Lewis BA (2007) Biology and control of the raspberry crown borer (Lepidoptera: Sesiidae). J Econ Entomol 100: 398-404

Medrzycki P, Montanari R, Bortolotti L, Sabatini AG, Maini S, Porrini C (2003) Effects of imidacloprid administered in sublethal doses on honey bee behaviour. Laboratory tests. Bull Insect 56:59-62

Medrzycki P, Sgolastra F, Bogo G, Tosi S, Venturi S (2011) Influence of some experimental conditions on the results of laboratory toxicological tests on honeybees. XI International Symposium "Hazards of pesticides to bees" Wageningen, The Netherlands, November 2-4

Mommaerts V, Reynders S, Boulet J, Besard L, Sterk G, Smagghe G (2010) Risk assessment for side-effects of neonicotinoids against bumblebees with and without impairing foraging behavior. Ecotoxicology 19:207-215

Morandin LA, Winston ML (2003) Effects of novel pesticides on bumble bee (Hymenoptera: Apidae) colony health and foraging ability. Environ Entomol 32:555-563

Moser SE, Obrycki JJ (2009) Non-target effects of neonicotinoid seed treatments; mortality of coccinellid larvae related to zoophytophagy. Biol Control 51:487-492

Mostert MA, Schoeman AS, van der Merwe M (2000) The toxicity of five insecticides to earthworms of the Pheretima group, using an artificial soil test. Pest Manag Sci 56:1093-1097

Mostert MA, Schoeman AS, van der Merwe M (2002) The relative toxicities of insecticides to earthworms of the Pheretima group (Oligochaeta). Pest Manag Sci 58:446-450

Mota-Sanchez D, Wise JC, Poppen RV, Gut LJ, Hollingworth RM (2008) Resistance of codling moth, Cydia pomonella (L.) (Lepidoptera: Tortricidae), larvae in Michigan to insecticides with different modes of action and the impact on field residual activity. Pest Manag Sci 64:881-890

Mullin CA, Frazier M, Frazier JL, Ashcraft S, Simonds R, van Engelsdorp D, Pettis JS (2010) High levels of miticides and agrochemicals in North American apiaries: implications for honey bee health. PLoS One 5:e9754

Nauen R, Ebbinghaus-Kintscher U, Schmuck R (2001) Toxicity and nicotinic acetylcholine receptor interaction of imidacloprid and its metabolites in Apis mellifera (Hymenoptera: Apidae). Pest Manag Sci 57:577-586

Nauen R, Ebbinghaus-Kintscher U, Salgado VL, Kaussmann M (2003) Thiamethoxam is a neonicotinoid precursor converted to clothianidin in insects and plants. Pestic Biochem Physiol 76:55-69

Neumann P, Carreck NL (2010) Honey bee colony loss. J Apic Res 49:16 , special issue

Nguyen BK et al (2009) Does imidacloprid seed-treated maize have an impact on honey bee mortality? J Econ Entomol 102:616-623

Nielsen SA, Brodsgaard CJ, Hansen H (2000) Effects on detoxification enzymes in different life stages of honey bees (Apis mellifera L., Hymenoptera: Apidae) treated with a synthetic pyrethroid (flumethrin). Altern Lab Anim 28:437-443

Ninsin KD (2004a) Acetamiprid resistance and cross-resistance in the diamondback moth, Plutella xylostella. Pest Manag Sci 60:839-841

Ninsin KD (2004b) Selection for resistance to acetamiprid and various other insecticides in the diamondback moth, Plutella xylostella $(\mathrm{L}$. (Lep., Plutellidae). J Appl Entomol 128:445-451

Ninsin KD, Miyata T (2003) Monitoring acetamiprid resistance in the diamondback moth, Plutella xylostella (L.) (Lepidoptera: Yponomeutidae). Appl Entomol Zool 38:517-521

Ninsin KD, Tanaka T (2005) Synergism and stability of acetamiprid resistance in a laboratory colony of Plutelia xylostella. Pest Manag Sci 61:723-727

Ninsin KD, Mo JC, Miyata T (2000) Decreased susceptibilities of four field populations of the diamondback moth, Plutella xylostella (L.) 
(Lepidoptera: Yponomeutidae), to acetamiprid. Appl Entomol Zool 35:591-595

Nyman AM, Hintermeister A, Schirmer K, Ashauer R (2013) The insecticide imidacloprid causes mortality of the freshwater Amphipod Gammarus pulex by interfering with feeding behavior. PLoS One 8: e62472

Oldroyd PB (2007) What's killing American honey bees? PLoS Biol 5: e168

Oliveira RA, Roat TC, Carvalho SM, Malaspina O (2013) Side-effects of thiamethoxam on the brain and midgut of the Africanized honeybee Apis mellifera (Hymenoptera: Apidae). Environ Toxicol 28 doi: $10.1002 /$ tox. 21842

Osborne JL, Martin AP, Shortall CR, Todd AD, Goulson D, Knight ME, Hale RJ, Sanderson RA (2008) Quantifying and comparing bumblebee nest densities in gardens and countryside habitats. J Appl Ecol 45:784-792

Osterberg JS, Darnell KM, Blickley TM, Romano JA, Rittschof D (2012) Acute toxicity and sub-lethal effects of common pesticides in postlarval and juvenile blue crabs, Callinectes sapidus. J Exp Mar Biol Ecol 424-425:5-14

Papachristos DP, Milonas PG (2008) Adverse effects of soil applied insecticides on the predatory coccinellid Hippodamia undecimnotata (Coleoptera: Coccinellidae). Biol Control 47:77-81

Paradis D, Bérail G, Bonmatin JM, Belzunces LP (2013) Sensitive analytical methods for 22 relevant insecticides of 3 chemical families in honey by GC-MS/MS and LC-MS/MS. Anal Bioanal Chem 406:621-633

Peck DC (2009) Comparative impacts of white grub (Coleoptera: Scarabaeidae) control products on the abundance of non-target soil-active arthropods in turfgrass. Pedobiologia 52:287-299

Peck DC, Olmstead D (2010) Neonicotinoid insecticides disrupt predation on the eggs of turf-infesting scarab beetles. Bull Entomol Res 100:689-700

Pedibhotla VK, Hall FR, Holmsen J (1999) Deposit characteristics and toxicity of fipronil formulations for tobacco budworm (Lepidoptera: Noctuidae) control on cotton. Crop Prot 18:493-499

Pestana JLT, Alexander AC, Culp JM, Baird DJ, Cessna AJ, Soares A (2009) Structural and functional responses of benthic invertebrates to imidacloprid in outdoor stream mesocosms. Environ Pollut 157: 2328-2334

Pettis JS, van Engelsdorp D, Johnson J, Dively G (2012) Pesticide exposure in honey bees results in increased levels of the gut pathogen Nosema. Naturwissenschaften 99:153-158

Pilling E, Campbell P, Coulson M, Ruddle N, Tornier I (2013) A fouryear field program investigating long-term effects of repeated exposure of honey bee colonies to flowering crops treated with thiamethoxam. PLoS One 8:e77193

Pochi D, Biocca M, Fanigliulo R, Pulcini P, Conte E (2012) Potential exposure of bees, Apis mellifera L., to particulate matter and pesticides derived from seed dressing during maize sowing. Bull Environ Contam Toxicol 89:354-61

Prabhaker N, Morse JG, Castle SJ, Naranjo SE, Henneberry TJ, Toscano NC (2007) Toxicity of seven foliar insecticides to four insect parasitoids attacking citrus and cotton pests. J Econ Entomol 100:1053-1061

Prabhaker N, Castle SJ, Naranjo SE, Toscano NC, Morse JG (2011) Compatibility of two systemic neonicotinoids, imidacloprid and thiamethoxam, with various natural enemies of agricultural pests. J Econ Entomol 104:773-781

Rahmani S, Bandani AR, Sabahi Q (2013) Effects of thiamethoxam in sublethal concentrations, on life expectancy (ex) and some other biological characteristics of Hippodamia variegata (Goeze) (Coleoptera: Coccinellidae). Int Res J App Basic Sci $4: 556-560$

Ramasubramanian T (2013) Persistence and dissipation kinetics of clothianidin in the soil of tropical sugarcane ecosystem. Water Air Soil Pollut 224:1468
Ramirez-Romero R, Chaufaux J, Pham-Delegue MH (2005) Effects of Cry1 Ab protoxin, deltamethrin and imidacloprid on the foraging activity and the learning performances of the honeybee Apis mellifera, a comparative approach. Apidologie 36: 601-611

Rasmussen JJ, McKnight US, Loinaz MC, Thomsen NI, Olsson ME, Bjerg PL, Binning PJ, Kronvang B (2013) A catchment scale evaluation of multiple stressor effects in headwater streams. Sci Total Environ 442:420-31

Reinhard J, Srinivasan MV, Zhang SW (2004) Scent-triggered navigation in honeybees. Nature 427:411-411

Reyes M, Franck P, Charmillot PJ, Ioriatti C, Olivares J et al (2007) Diversity of insecticide resistance mechanisms and spectrum in European populations of the Codling moth, Cydia pomonella. Pest Manag Sci 63:890-902

Rhainds M, Sadof C (2009) Control of bagworms (Lepidoptera: Psychidae) using contact and soil-applied systemic insecticides. J Econ Entomol 102:1164-1169

Riaz MA, Chandor-Proust A, Dauphin-Villemant C, Poupardin R, Jones CM, Strode C, Régent-Kloeckner M, David JP, Reynaud S (2013) Molecular mechanisms associated with increased tolerance to the neonicotinoid insecticide imidacloprid in the dengue vector Aedes aegypti. Aquat Toxicol 126:326-337. doi:10.1016/j.aquatox.2012. 09.010

Richarz N, Neumann D, Wipking W (1989) Untersuchungen zur Ökologie des Apollofalters (Parnassius apollo vinningensis Stichel 1899, Lepidoptera, Papilionidae) im Weinbaugebiet der unteren Mosel. Mitt der Assoc Rheinisch-Westfälischer Lepidopterologen 5:108-259

Rodrick GB (2008) Effect of temperature, salinity, and pesticides on oyster hemocyte activity. Florida Water Resour J 86:4-14. doi:10. 2175/SJWP(2008)1

Rogers MA, Krischik VA, Martin LA (2007) Effect of soil application of imidacloprid on survival of adult green lacewing, Chrysoperla carnea (Neuroptera: Chrysopidae), used for biological control in greenhouse. Biol Control 42:172-177

Rondeau G, Sanchez-Bayo F, Tennekes HA, Decourtye A, RamirezRomero R, Desneux N (2014) Delayed and time-cumulative toxicity of imidacloprid in bees, ants and termites. Nat Sc Rep 4:5566. doi: 10.1038/srep05566

Rundlöf M, Bengtsson J, Smith HG (2008) Local and landscape effects of organic farming on butterfly species richness and abundance. J Appl Ecol 45:813-820

Rust MK, Reierson DA, Klotz JH (2004) Delayed toxicity as a critical factor in the efficacy of aqueous baits for controlling Argentine ants (Hymenoptera: Formicidae). J Econ Entomol 97:1017-1024

Sánchez-Bayo F (2006) Comparative acute toxicity of organic pollutants and reference values for crustaceans. I. Branchiopoda, Copepoda and Ostracoda. Environ Pollut 139:385-420

Sánchez-Bayo F (2009) From simple toxicological models to prediction of toxic effects in time. Ecotoxicology 18:343-354

Sanchez-Bayo F, Goka K (2014) Pesticide residues and bees-a risk assessment. PLoS One 9:e94482

Sanchez-Bayo F, Kouchi G (2012) Evaluation of suitable endpoints for assessing the impacts of toxicants at the community level. Ecotoxicology 21:667-680. doi:10.1007/s10646-011-0823-x

Saour G (2008) Effect of thiacloprid against the potato tuber moth Phthorimaea operculella Zeller (Lepidoptera: Gelechiidae). J Pest Sci 81:3-8

Sardo AM, Soares AMVM (2010) Assessment of the effects of the pesticide imidacloprid on the behaviour of the aquatic Oligochaete Lumbriculus variegatus. Arch Environ Contam Toxicol 58:648-656

Sarkar MA, Roy S, Kole RK, Chowdhury A (2001) Persistence and metabolism of imidacloprid in different soils of West Bengal. Pest Manag Sci 57:598-602 
Sayyed AH, Crickmore N (2007) Selection of a field population of diamondback moth (Lepidoptera: Plutellidae) with acetamiprid maintains, but does not increase, cross-resistance to pyrethroids. J Econ Entomol 100:932-938

Sayyed AH, Wright DJ (2004) Fipronil resistance in the diamondback moth (Lepidoptera: Plutellidae): inheritance and number of genes involved. J Econ Entomol 97:2043-2050

Schäfer RB, vd Ohe P, Rasmussen J, Kefford B, Beketov M, Schulz R, Liess M (2012) Thresholds for the effects of pesticides on invertebrate communities and leaf breakdown in stream ecosystems. Environ Sci Tech 46:5134-5142

Schmidt A (1997) Zur aktuellen situation des mosel-apollofalters parnassius apollo vinningensis Stichel, 1899 (Lep., Papilionidae). Melanargia 9:38-47

Schmuck R (2004) Effects of a chronic dietary exposure of the honeybee Apis mellifera (Hymenoptera: Apidae) to imidacloprid. Arch Environ Contam Toxicol 47:471-478

Schmuck R, Schoning R, Stork A, Schramel O (2001) Risk posed to honeybees (Apis mellifera L. Hymenoptera) by an imidacloprid seed dressing of sunflowers. Pest Manag Sci 57:225-238

Schmuck R, Stadler T, Schmidt HW (2003) Field relevance of a synergistic effect observed in the laboratory between an EBI fungicide and a chloronicotinyl insecticide in the honeybee (Apis mellifera $\mathrm{L}$, Hymenoptera). Pest Manag Sci 59:279-286

Schneider CW, Tautz J, Grünewald B, Fuchs S (2012) RFID tracking of sublethal effects of two neonicotinoid insecticides on the foraging behavior of Apis mellifera. PLoS One 7:e30023

Scholer J, Krischik V (2014) Chronic exposure of imidacloprid and clothianidin reduce queen survival, foraging, and nectar storing in colonies of Bombus impatiens. PLoS One 9:e91573

Scott-Dupree CD, Conroy L, Harris CR (2009) Impact of currently used or potentially useful insecticides for canola agroecosystems on Bombus impatiens (Hymenoptera: Apidae), Megachile rotundata (Hymentoptera: Megachilidae), and Osmia lignaria (Hymenoptera: Megachilidae). J Econ Entomol 102:177-182

Seagraves MP, Lundgren JG (2012) Effects of neonicitinoid seed treatments on soybean aphid and its natural enemies. J Pest Sci 85:125-132

Sergio M (2013) GMO and pesticide experiments in Hawaii: the poisoning of paradise. Huffington Post. http://www.huffingtonpost.com/ maggie-sergio/gmo-pesticide-experiments_b_3513496.html

Setamou M, Rodriguez D, Saldana R, Schwarzlose G, Palrang D et al (2010) Efficacy and uptake of soil-applied imidacloprid in the control of Asian citrus psyllid and a citrus leafminer, two foliarfeeding citrus pests. J Econ Entomol 103:1711-1719

Sgolastra F, Renzi T, Draghetti S, Medrzycki P, Lodesani M, Maini S, Pottini C (2012) Effects of neonicotinoid dust from maize seeddressing on honey bees. Bullf Insect 65:273-280

Sheehan C, Kirwan L, Connolly J, Bolger T (2008) The effects of earthworm functional diversity on microbial biomass and the microbial community level physiological profile of soils. Eur J Soil Biol 44:65-70

Shi ZH, Guo SJ, Lin WC, Liu SS (2004) Evaluation of selective toxicity of five pesticides against Plutella xylostella (Lep: Plutellidae) and their side-effects against Cotesia plutellae (Hym: Braconidae) and Oomyzus sokolowskii (Hym: Eulophidae). Pest Manag Sci 60:12131219

Siegfried BD, Spencer T, Marcon PCRG (1999) Susceptibility of European corn borer, Ostrinia nubilalis (Hubner) (Lepidoptera: Pyralidae) neonate larvae to fipronil. J Agric Urban Entomol 16: 273-278

Simon-Delso N, Amaral-Rogers V, Belzunces LP, Bonmatin J-M, Chagnon M, Downs C, Furlan L, Gibbons DW, Giorio C, Girolami V, Goulson D, Kreutzweiser DP, Krupke C, Liess M, Long E, McField M, Mineau P, Mitchell EAD, Morrissey CA, Noome DA, Pisa L, Settele J, Stark JD, Tapparo A, Van Dyck H, Van Praagh J, Van der Sluijs JP, Whitehorn PR, Wiemers M (2014)
Systemic insecticides (neonicotinoids and fipronil): trends, uses, mode of action and metabolites. Environ Sci Pollut Res (this issue)

Sinha SN, Lakhani KH, Davis BNK (1990) Studies on the toxicity of insecticidal drift to the first instar larvae of the large white butterfly Pieris brassicae (Lepidoptera: Pieridae). Ann Appl Biol 116:27-41

Smith SF, Krischick VA (1999) Effects of systemic imidacloprid on Coleomegilla maculata (Coleoptera: Coccinellidae). Environ Entomol 28:1189-1195

Smith JF, Catchot AL, Musser FR, Gore J (2013) Effects of aldicarb and neonicotinoid seed treatments on twospotted spider mite on cotton. J Econ Entomol 106:807-815

Smodis Skerl MI, Velikonja Bolta S, Basa Cesnik H, Gregorc A (2009) Residues of pesticides in honeybee (Apis mellifera carnica) bee bread and in pollen loads from treated apple orchards. Bull Environ Contam Toxicol 83:374-7

Song MY, Brown JJ (1998) Osmotic effects as a factor modifying insecticide toxicity on Aedes and Artemia. Ecotoxicol Environ Saf 41:195-202

Song MY, Stark JD, Brown JJ (1997) Comparative toxicity of four insecticides, including imidacloprid and tebufenozide, to four aquatic arthropods. Environ Toxicol Chem 16:2494-2500

Stapel JO, Cortesero AM, Lewis WJ (2000) Disruptive sublethal effects of insecticides on biological control: altered foraging ability and life span of a parasitoid after feeding on extrafloral nectar of cotton treated with systemic insecticides. Biol Control 17:243-249

Stara J, Kocourek F (2007) Insecticidal resistance and cross-resistance in populations of Cydia pomonella (Lepidoptera: Tortricidae) in central Europe. J Econ Entomol 100:1587-95

Stark JD, Banks JE (2003) Population-level effects of pesticides and other toxicants on arthropods. Annu Rev Entomol 48:505-519

Stark JD, Jepson PC, Mayer DF (1995) Limitations to use of topical toxicity data for predictions of pesticide side effects in the field. $\mathrm{J}$ Econ Entomol 88:1081-1088

Starner K, Goh KS (2012) Detections of the neonicotinoid insecticide imidacloprid in surface waters of three agricultural regions of California, USA, 2010-2011. Bull Environ Contam Toxicol, 1-6

Stokstad E (2007) The case of the empty hives. Science 316:970-972

Stoughton SJ, Liber K, Culp J, Cessna A (2008) Acute and chronic toxicity of imidacloprid to the aquatic invertebrates Chironomus tentans and Hyalella azteca under constant- and pulse-exposure conditions. Arch Environ Contam Toxicol 54:662-673

Stygar D, Michalczyk K, Dolezych B, Nakonieczny M, Migula P et al (2013) Digestive enzymes activity in subsequent generations of Cameraria ohridella larvae harvested from horse chestnut trees after treatment with imidacloprid. Pestic Biochem Physiol 105:5-12

Suchail S, Guez D, Belzunces LP (2000) Characteristics of imidacloprid toxicity in two Apis mellifera subspecies. Environ Toxicol Chem 19: 1901-1905

Suchail S, Guez D, Belzunces LP (2001) Discrepancy between acute and chronic toxicity induced by imidacloprid and its metabolites in Apis mellifera. Environ Toxicol Chem 20:2482-2486

Suchail S, De Sousa G, Rahmani R, Belzunces LP (2004a) In vivo distribution and metabolisation of $\left[{ }^{14} \mathrm{C}\right]$-imidacloprid in different compartments of Apis mellifera L. Pest Manag Sci 60:1056-1062

Suchail S, Debrauwer L, Belzunces LP (2004b) Metabolism of imidacloprid in Apis mellifera. Pest Manag Sci 60:291-296

Symington CA (2003) Lethal and sublethal effects of pesticides on the potato tuber moth, Phthorimaea operculella (Zeller) (Lepidoptera: Gelechiidae) and its parasitoid Orgilus lepidus Muesebeck (Hymenoptera: Braconidae). Crop Prot 22:513-519

Szczepaniec A, Creary SF, Laskowski KL, Nyrop JP, Raupp MJ (2011) Neonicotinoid insecticide imidacloprid causes outbreaks of spider mites on elm trees in urban landscapes. PLoS One 6:e20018 
Szczepaniec A, Raupp MJ, Parker RD, Kerns D, Eubanks MD (2013) Neonicotinoid insecticides alter induced defenses and increase susceptibility to spider mites in distantly related crop plants. PLoS One 8:e62620

Tapparo A, Marton D, Giorio C, Zanella A, Solda' L, Marzaro M, Vivan L, Girolami V (2012) Assessment of the environmental exposure of honeybees to the particulate matter containing neonicotinoid insecticides coming from corn coated seeds. Environ Sci Tech 46:25922599

Tarmann G (2009) Die Vinschger Trockenrasen - Ein Zustandsbericht auf basis der bioindikatoren Tagfalter und widderchen (Lepidoptera: Rhopalocera, Zygaenidae). Sci Yearb Tyrolean State Mus 2:307350

Tasei JN, Lerin J, Ripault G (2000) Sub-lethal effects of imidacloprid on bumblebees, Bombus terrestris (Hymenoptera: Apidae), during a laboratory feeding test. Pest Manag Sci 56:784-788

Tasei JN, Ripault G, Rivault E (2001) Hazards of imidacloprid seed coating to Bombus terrestris (Hymenoptera: Apidae) when applied to sunflower. J Econ Entomol 94:623-627

Taverner PD, Sutton C, Cunningham NM, Dyson C, Lucas N et al (2011) Efficacy of several insecticides alone and with horticultural mineral oils on light brown apple moth (Lepidoptera: Tortricidae) eggs. J Econ Entomol 104:220-224

Taverner PD, Sutton C, Cunningham NM, Myers SW (2012) The potential of mineral oils alone and with reduced rates of insecticides for the control of light brown apple moth, Epiphyas postvittana (Walker) (Lepidoptera: Tortricidae), on nursery plants. Crop Prot 42:83-87

Teeters BS, Johnson RM, Ellis MD, Siegfried BD (2012) Using videotracking to assess sublethal effects of pesticides on honey bees (Apis mellifera L.). Environ Toxicol Chem 31:1349-1354

Tennekes HA (2010) The significance of the Druckrey-Küpfmüller equation for risk assessment - the toxicity of neonicotinoid insecticides to arthropods is reinforced by exposure time. Toxicology 276:1-4

Tennekes HA (2011) The significance of the Druckrey-Küpfmüller equation for risk assessment - the toxicity of neonicotinoid insecticides to arthropods is reinforced by exposure time: responding to a letter to the editor by Drs. C. Maus and R. Nauen of Bayer CropScience AG. Toxicology 280:173-175

Tennekes HA, Sánchez-Bayo F (2012) Time-dependent toxicity of neonicotinoids and other toxicants: implications for a new approach to risk assessment. J Environ Anal Toxicol S4:001. doi:10.4172/ 2161-0525.S4-001

Tennekes HA, Sánchez-Bayo F (2013) The molecular basis of simple relationships between exposure concentration and toxic effects with time. Toxicology 309:39-51

Thany SH, Gauthier M (2005) Nicotine injected into the antennal lobes induces a rapid modulation of sucrose threshold and improves shortterm memory in the honeybee Apis mellifera. Brain Res 1039:216219

Thany SH, Lenaers G, Crozatier M, Armengaud C, Gauthier M (2003) Identification and localization of the nicotinic acetylcholine receptor alpha3 mRNA in the brain of the honeybee, Apis mellifera. Insect Mol Biol 12:255-262

Thompson HM, Maus C (2007) The relevance of sublethal effects in honey bee testing for pesticide risk assessment. Pest Manag Sci 63: $1058-1061$

Tomé HVV, Martins GF, Lima MAP, Campos LAO, Guedes RNC (2012) Imidacloprid-induced impairment of mushroom bodies and behavior of the native stingless bee Melipona quadrifasciata anthidioides. PLoS One 7:e38406

Tomizawa M, Maltby D, Talley TT, Durkin KA, Medzihradszky KF, Burlingame AL, Taylor P, Casida JE (2008) Atypical nicotinic agonist bound conformations conferring subtype selectivity. Proc Natl Acad Sci U S A 105:1728-1732
Tu C, Wang Y, Duan W, Hertl P, Tradway L, Brandenburg R, Lee D, Snell M, Hu S (2011) Effects of fungicides and insecticides on feeding behavior and community dynamics of earthworms: implications for casting control in turfgrass systems. Appl Soil Ecol 47:31-36

Valdovinos-Núñez J, Quezada-Euán JG, Ancona-Xiu P, Moo-Valle H, Carmona A, Sanchez ER (2009) Comparative toxicity of pesticides to stingless bees (Hymenoptera: Apidae: Meliponini). J Econ Entomol 102:1737-1742

Van den Brink PJ, Roelsma J, van Nes EH, Scheffer M, Brock TCM (2002) PERPEST model: a case-based reasoning approach to predict ecological risks of pesticides. Environ Toxicol Chem 21:2500 2506

Van der Sluijs JP, Simon-Delso S, Goulson D, Maxim L, Bonmatin JM, Belzunces LP (2013) Neonicotinoids, bee disorders and the sustainability of pollinator services. Curr Opin Environ Sustain 5:293-305

Van der Zee R, Pisa L, Andonov S, Brodschneider R, Charriere JD et al (2012) Managed honey bee colony losses in Canada, China, Europe, Israel and Turkey, for the winters of 2008-9 and 2009-10. J Apic Res 51:91-114. doi:10.3896/ibra.1.51.1.12

Van Dijk TC, van Staalduinen MA, van der Sluijs JP (2013) Macroinvertebrate decline in surface water polluted with imidacloprid. PLoS One 8:e62374. doi:10.1371/journal.pone.0062374

Van Engelsdorp D, Meixner MD (2010) A historical review of managed honey bee populations in Europe and the United States and the factors that may affect them. J Invertebr Pathol 103:80-95

Vandame R, Meled M, Colin ME, Belzunces LP (1995) Alteration of the homing-flight in the honey bee Apis mellifera L. exposed to sublethal dose of deltamethrin. Environ Toxicol Chem 14:855-860

Vidau C, Diogon M, Aufauvre J, Fontbonne R, Vigues B, Brunet JL, Texier C, Biron DG, Blot N, El Alaoui H, Belzunces LP, Delbac F (2011) Exposure to sublethal doses of fipronil and thiacloprid highly increases mortality of honeybees previously infected by Nosema ceranae. PLoS One 6:e21550. doi:10.1371/journal.pone.0021550

Vijver MG, van den Brink PJ (2014) Macro-invertebrate decline in surface water polluted with imidacloprid: a rebuttal and some new analyses. PLoS One 9:e89837

Villanueva-Jimenez JA, Hoy MA (1998) Toxicity of pesticides to the citrus leafminer and its parasitoid Ageniaspis citricola evaluated to assess their suitability for an IPM program in citrus nurseries. Biocontrol 43:357-388

Volkov EM, Nurullin LF, Nikolsky E, Vyskocil F (2007) Miniature excitatory synaptic ion currents in the earthworm Lumbricus terrestris body wall muscles. Physiol Res 56:655-658

Voudouris CC, Sauphanor B, Franck P, Reyes M, Mamuris Z et al (2011) Insecticide resistance status of the codling moth Cydia pomonella (Lepidoptera: Tortricidae) from Greece. Pestic Biochem Physiol 100:229-238

Wang M, Grimm V (2010) Population models in pesticide risk assessment: lessons from assessing population-level effects, recovery, and alternative exposure scenarios from modeling a small mammal. Environ Toxicol Chem 29:1292-1300

Wang AH, Wu JC, Yu YS, Liu JL, Yue JF et al (2005) Selective insecticide-induced stimulation on fecundity and biochemical changes in Tryporyza incertulas (Lepidoptera: Pyralidae). J Econ Entomol 98:1144-1149

Wang Y, Cang T, Zhao X, Yu R, Chen L, Wu C, Wang Q (2012a) Comparative acute toxicity of twenty-four insecticides to earthworm, Eisenia fetida. Ecotoxicol Environ Saf 79:122-128

Wang Y, Wu S, Chen L, Wu C, Yu R, Wang Q, Zhao X (2012b) Toxicity assessment of 45 pesticides to the epigeic earthworm Eisenia fetida. Chemosphere 88:484-491

Ward GS (1990) NTN 33893 technical: acute toxicity to the mysid, Mysidopsis bahia, under flow-through test conditions. Toxicon Environmental Sciences, Jupiter, Florida (performing laboratory). 
Mobay Corporation, Kansas City, Missouri (submitting laboratory). Mobay Report No. 100355. 46 pp

Ward GS 1991. NTN 33893 technical: chronic toxicity to the mysid Mysidopsis bahia under flow-through conditions. Toxicon Environmental Sciences, Jupiter, FL. 87 pp. Miles Report No. 101347

Weibull AC, Bengtsson J, Nohlgren E (2000) Diversity of butterflies in the agricultural landscape: the role of farming system and landscape heterogeneity. Ecography 23:743-750

Whitehorn PR, O'Connor S, Wackers FL, Goulson D (2012) Neonicotinoid pesticide reduces bumble bee colony growth and queen production. Science 336:351-352

Wise JC, Jenkins PE, Vander Poppen R, Isaacs R (2010) Activity of broad-spectrum and reduced-risk insecticides on various life stages of cranberry fruitworm (Lepidoptera: Pyralidae) in highbush blueberry. J Econ Entomol 103:1720-1728

Wu JY, Anelli CM, Sheppard WS (2011) Sub-lethal effects of pesticide residues in brood comb on worker honey bee (Apis mellifera) development and longevity. PLoS One 6:e14720

Wu JY, Smart MD, Anelli CM, Sheppard WS (2012) Honey bees (Apis mellifera) reared in brood combs containing high levels of pesticide residues exhibit increased susceptibility to Nosema (Microsporidia) infection. J Invertebr Pathol 109:326-329

Yamada T, Yamada K, Wada N (2012) Influence of dinotefuran and clothianidin on a bee colony. Japan J Clin Ecol 21:10-23

Yang EC, Chuang YC, Chen YL, Chang LH (2008) Abnormal foraging behavior induced by sublethal dosage of imidacloprid in the honey bee (Hymenoptera: Apidae). J Econ Entomol 101:17431748
Yang EC, Chang HC, Wu WY, Chen YW (2012) Impaired olfactory associative behavior of honeybee workers due to contamination of imidacloprid in the larval stage. PLoS One 7:e49472

Youn YN, Seo MJ, Shin JG, Jang C, Yu YM (2003) Toxicity of greenhouse pesticides to multicolored Asian lady beetles, Harmonia axyridis (Coleoptera: Coccinellidae). Biol Control 28:164-170

Yu YS, Xue S, Wu JC, Wang F, Liu JL et al (2007a) Distribution of imidacloprid residues in different parts of rice plants and its effect on larvae and adult females of Chilo suppressalis (Lepidoptera: Pyralidae). J Econ Entomol 100:375-380

Yu YS, Xue S, Wu JC, Wang F, Yang GQ (2007b) Changes in levels of juvenile hormone and molting hormone in larvae and adult females of Chilo suppressalis (Lepidoptera: Pyralidae) after imidacloprid applications to rice. J Econ Entomol 100:1188-1193

Yue B, Wilde GE, Arthur F (2003) Evaluation of thiamethoxam and imidacloprid as seed treatments to control European corn borer and Indianmeal moth (Lepidoptera: Pyralidae) larvae. J Econ Entomol 96:503-509

Zang Y, Zhong Y, Luo Y, Kong ZM (2000) Genotoxicity of two novel pesticides for the earthworm, Eisenia fetida. Environ Pollut 108: 271-278

Zeng CX, Wang JJ (2010) Influence of exposure to imidacloprid on survivorship, reproduction and vitellin content of the carmine spider mite, Tetranychus cinnabarinus. J Insect Sci 10:20

Zhou LJ, Huang JG, Xu HH (2011) Monitoring resistance of field populations of diamondback moth Plutella xylostella L. (Lepidoptera: Yponomeutidae) to five insecticides in South China: a ten-year case study. Crop Prot 30:272-278 